\title{
ARTICLE OPEN \\ Bcl-3 promotes Wnt signaling by maintaining the acetylation of $\beta$-catenin at lysine 49 in colorectal cancer
}

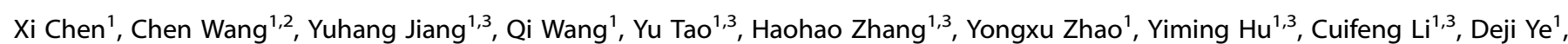
Dandan Liu ${ }^{1}$, Wenxia Jiang ${ }^{1}$, Eugene Y. Chin ${ }^{1}$, Sheng Chen ${ }^{4}$, Yongzhong Liu ${ }^{5}$, Mingliang Wang ${ }^{6}$, Sanhong Liu ${ }^{1,2}$ and Xiaoren Zhang ${ }^{1,3}$

Wnt/ $\beta$-catenin signaling plays a critical role in colorectal cancer (CRC) tumorigenesis and the homeostasis of colorectal cancer stem cells (CSCs), but its molecular mechanism remains unclear. B-cell lymphoma 3 (Bcl-3), a member of the IkB family, is overexpressed in $\mathrm{CRC}$ and promotes tumorigenicity. Here, we report a novel function of $\mathrm{BCl}-3$ in maintaining colorectal CSC homeostasis by activating Wnt/ $\beta$-catenin signaling. Silencing Bcl-3 suppresses the self-renewal capacity of colorectal CSCs and sensitizes CRC cells to chemotherapeutic drugs through a decrease in Wnt/ $\beta$-catenin signaling. Moreover, our data show that Bcl-3 is a crucial component of Wnt/ $\beta$-catenin signaling and is essential for $\beta$-catenin transcriptional activity in CRC cells. Interestingly, Wnt3a increases the level and nuclear translocation of $\mathrm{Bcl}-3$, which binds directly to $\beta$-catenin and enhances the acetylation of $\beta$-catenin at lysine 49 (Ac-K49- $\beta$-catenin) and transcriptional activity. Bcl-3 depletion decreases the Ac-K49- $\beta$-catenin level by increasing the level of histone deacetylase 1 to remove acetyl groups from $\beta$-catenin, thus interrupting Wnt/ $\beta$-catenin activity. In CRC clinical specimens, $\mathrm{BCl}-3$ expression negatively correlates with the overall survival of $\mathrm{CRC}$ patients. A significantly positive correlation was found between the expression of $\mathrm{BCl}-3$ and Ac-K49- $\beta$-catenin. Collectively, our data reveal that Bcl-3 plays a crucial role in CRC chemoresistance and colorectal CSC maintenance via its modulation of the Ac-K49- $\beta$-catenin, which serves as a promising therapeutic target for CRC.

\section{INTRODUCTION}

Colorectal cancer (CRC) is the fourth leading cause of cancer deaths, and the incidence rate ranks third worldwide. ${ }^{1}$ Cancer stem cells (CSCs) have the capacity for self-renewal, tumor initiation, tumor growth, metastasis, ${ }^{2}$ and resistance to chemotherapy. ${ }^{3}$ Therefore, the elucidation of the mechanisms that maintain colorectal CSCs is essential for the development of new therapeutic treatments in CRC.

Colorectal CSCs can be identified by a variety of cell surface markers, including CD133, CD44, and CD24. ${ }^{4,5}$ Persistent activation of canonical Wnt signaling is crucial for the tumorigenesis of CRC (refs. ${ }^{6,7}$ ) and stemness maintenance of colorectal CSCs. ${ }^{8,9} \mathrm{Wnt}$ signaling is activated when Wnt ligands bind to the membrane receptors Frizzled and LDL receptor-related protein 5 or 6 . Subsequently, $\beta$-catenin in the cytoplasm is released from the $\beta$-catenin destruction complex, and stabilized $\beta$-catenin translocates to the nucleus to form a transcriptional complex with LEF/ TCF. $^{6}$ In the absence of Wnt ligand treatment, $\beta$-catenin in the cytoplasm is rapidly degraded by a multiprotein complex that includes APC (adenomatous polyposis coli), AXIN, and GSK-3 (glycogen synthase kinase-3) kinase. One of the core components of the Wnt/ $\beta$-catenin destruction complex is GSK-3. Under normal circumstances, GSK-3 phosphorylates $\beta$-catenin on its N-terminal Thr41, Ser37, and Ser33 residues. ${ }^{10}$ Thereafter, phosphorylated $\beta$-catenin is ubiquitinated and degraded by the proteasome. ${ }^{11}$

$\mathrm{B}$-cell lymphoma $3(\mathrm{BCl}-3)$ is a member of the IKB family, and it is an important transcriptional regulator that forms complexes with p50 and p52 on DNA. ${ }^{12,13} \mathrm{Bcl}-3$ promotes breast cancer metastasis ${ }^{14}$ by stabilizing Smad3/TGF $\beta$ signaling. ${ }^{15}$ In glioblastoma cells, Bcl-3 significantly facilitated proliferation by stabilizing the expression of STAT3, p-STAT3, and STAT3 signaling target genes, including $\mathrm{BCl}-2, \mathrm{MCL}-1$, and cyclin D1. ${ }^{16}$ Recently, the function of $\mathrm{BCl}-3$ in $\mathrm{CRC}$ has been reported by various research groups. First, $\mathrm{BCl}-3$ was found to promote CRC cell growth by stabilizing the c-Myc protein level and regulating ERK signaling. ${ }^{17}$ In addition, $\mathrm{BCl}-3$ promotes $\mathrm{CRC}$ tumorigenesis based on the activation of AKT signaling. ${ }^{18}$ Finally, Bcl-3 suppresses inflammation-associated colon tumorigenesis in epithelial cells by dampening tumorigenic NF-KB signaling. ${ }^{19}$ Moreover, previously uncovered evidence demonstrated the function of $\mathrm{BCl}-3$ in pluripotency maintenance. Bcl-3 functions as a downstream molecule of LIF/STAT3 signaling and positively regulates

\footnotetext{
${ }^{1}$ CAS Key Laboratory of Tissue Microenvironment and Tumor, Shanghai Institute of Nutrition and Health, Shanghai Institutes for Biological Sciences, University of Chinese Academy of Sciences, Chinese Academy of Sciences, Shanghai 200025, China; ${ }^{2}$ Shanghai Institute for Advanced Immunochemical Studies, ShanghaiTech University, Shanghai 201210, China; ${ }^{3}$ Affiliated Cancer Hospital \& Institute of Guangzhou Medical University, Guangzhou Municipal and Guangdong Provincial Key Laboratory of Protein Modification and Degradation, State Key Laboratory of Respiratory Disease, Guangzhou 510000, China; ${ }^{4}$ Renji Hospital, Shanghai Jiao Tong University School of Medicine, Shanghai 200025, China; ${ }^{5}$ State Key Laboratory of Oncogenes and Related Genes, Shanghai Cancer Institute, Renji Hospital, Shanghai Jiao Tong University School of Medicine, Shanghai 200032, China and ${ }^{6}$ Department of General Surgery, Ruijin Hospital, Shanghai Jiao Tong University School of Medicine, Shanghai 200025, China

Correspondence: Mingliang Wang (wml_2902@163.com) or Sanhong Liu (liush@shanghaitech.edu.cn) or Xiaoren Zhang (xrzhang@sibs.ac.cn)

These authors contributed equally: Xi Chen, Chen Wang
}

Received: 16 September 2019 Revised: 24 December 2019 Accepted: 18 February 2020

Published online: 01 May 2020 
pluripotency genes, including Oct4, Sox2, and Nanog, in mouse embryonic stem cells (mESCs). ${ }^{20,21}$

Due to the overactivation of $\mathrm{Bcl}-3$ and $\beta$-catenin that occurs in many cancers, we hypothesize that there is a potential functional relationship between these two transcriptional regulators. In this study, we explored the possibility of Bcl-3 as a component in Wnt/ $\beta$-catenin signaling and determined the biological role of $\mathrm{BCl}-3$ in CRC progression, as well as in colorectal CSCs.

\section{RESULTS}

$\mathrm{Bcl}-3$ promotes a stem cell-like phenotype in CRC cells in vitro Prompted by the results of previous studies in which $\mathrm{BCl}-3$ has a potential oncogenic role in $\mathrm{CRC},{ }^{17}$ as well as the research that $\mathrm{Bcl}-$ 3 is necessary for pluripotency and self-renewal of $\mathrm{mESCs},{ }^{20,21}$ we hypothesized that $\mathrm{BCl}-3$ may play an important role in maintaining the homeostasis of colorectal CSCs. The in vitro stemness capability of cells was assessed by flow cytometry to examine the percentage of cells coexpressing CD44 and CD133. ${ }^{22-24}$ The knockdown (KD) efficiency of two different shRNA sequences targeting $\mathrm{BCl}-3$ is shown in Supplementary Fig. $1 \mathrm{a}$. Bcl-3 KD remarkably impaired the generation of $\mathrm{CD} 44^{+} \mathrm{CD} 133^{+}$cells in CRC cells (Fig. 1a). Additionally, Bcl-3 depletion dramatically reduced the number and average diameter of spheres in tumorsphere formation assays in HCT116 and SW620 cells (Fig. 1b, c). Therefore, these results indicate that $\mathrm{BCl}-3$ is required for the homeostasis of colorectal CSCs and that it promotes the proliferation of CSCs.

Then, we detected the expression of several CSC-related genes, such as CD44, CD133, SOX2, OCT4, NANOG, and CTNNB1. The results of q-RT-PCR revealed that the expression of CD133 and SOX2 was significantly reduced in $\mathrm{BCl}-3 \mathrm{KD}$ cells. The mRNA level of CTNNB1 barely changed in both cell lines when $\mathrm{BCl}-3$ was silenced (Fig. 1d). Then, we performed immunoblot assays to confirm the downregulation of SOX2 and CD133 in both cell lines (Fig. 1e). To further assess the relevance between $\mathrm{BCl}-3$ and $\mathrm{CSC}$-related genes, we analyzed the expression of $\mathrm{BCl}-3$, SOX2, and CD133 in 148 patient samples from the bioinformatics website R2: Genomics Analysis and Visualization Platform (http://r2.amc.nl). Linear regression analyses showed that the mRNA level of $\mathrm{Bcl}-3$ was positively correlated with CD133 and SOX2 (Supplementary Fig. $1 \mathrm{~b}$ ). Together, these results indicate that $\mathrm{BCl}-3$ maintains the stemness of CRCs by regulating the expression of stemnessrelated genes.

$\mathrm{Bcl}-3$ enhances tumorigenicity, and $\mathrm{Bcl}-3$ depletion enhances drug sensitivity

To evaluate the effect of $\mathrm{BCl}-3$ on the tumorigenicity of $\mathrm{CRC}$ cells in vivo, we first confirmed the KD efficiency in HCT116 cells (Supplementary Fig. 2a, b). The shBcl-3-1 sequence was used in the experiments below. Three doses of Bcl-3-silenced HCT116 cells and the corresponding control cells were subcutaneously inoculated into BALB/c nude mice. As shown in Fig. 2a, b, Bcl-3 depletion significantly suppressed xenograft tumor growth and tumorigenic cell frequency. Moreover, Bcl-3 KD led to a $>90 \%$ reduction in CSC frequency, as demonstrated by in vivo limited dilution assays (Fig. $2 \mathrm{C}$ ), suggesting that $\mathrm{BCl}-3 \mathrm{KD}$ reduced tumorinitiating capacity.

Due to the potential contribution of CSCs in chemoresistance, we wanted to determine whether $\mathrm{Bcl}-3$ is involved in drug resistance. We first assessed the expression of $\mathrm{Bcl}-3$ after 5fluorouracil (5-FU) and oxaliplatin (Oxal) treatment of HCT116 and SW620 cells. There was a significant increase in the mRNA level of $\mathrm{BCl}-3$ after 5-FU or Oxal treatment in both cell lines (Fig. 2d). The same result was found on the online database ONCOMINE Colorectal Dataset (https://www.oncomine.org/resource/main. html) ${ }^{25}$ (Supplementary Fig. 2c). Therefore, we determined the sensitivity of HCT116 and SW620 cells to 5-FU and Oxal after the depletion of BCl-3, using MTT and FACS assays. BCl-3 depletion markedly reduced chemoresistance and increased the percentage of apoptotic cells upon treatment with 5-FU and Oxal (Fig. 2e-h). These data suggest that $\mathrm{BCl}-3$ depletion increases 5-FU- and Oxalinduced cell apoptosis, and enhances drug sensitivity in CRC cells.

Wnt3a increases $\mathrm{Bcl}-3$ protein expression via GSK-3 kinase activity $\mathrm{Bcl}-3$ can be unregulated by several cytokines, ${ }^{26-33}$ which prompted us to examine whether $\mathrm{BCl}-3$ responds to Wnt ligands. The expression of $\mathrm{Bcl}-3$ increased after $1 \mathrm{~h}$ of Wnt3a treatment and reached maximal induction after $4 \mathrm{~h}$ (Fig. 3a). However, $\mathrm{BCl}-3$ mRNA levels did not increase upon Wnt3a treatment (Fig. 3a). After inhibition of new protein synthesis by cycloheximide (CHX), Wnt3a treatment resulted in increased $\mathrm{BCl}-3$ compared with the control treatment, which indicates a decrease in endogenous $\mathrm{Bcl}-3$ degradation after Wnt3a treatment (Fig. 3b). Cells were treated with the proteasome inhibitor MG-132 had an elevated Bcl-3 level (Supplementary Fig. 3a, b). However, Wnt3a stimulation did not increase Bcl-3 expression when the cells were pretreated with MG132 (Supplementary Fig. 3a, b). These results show that Wnt3ainduced $\mathrm{BCl}-3$ expression through the ubiquitin-proteasome degradation system. Then, we determined the possible changes in the ubiquitination of $\mathrm{Bcl}-3$. Consistent with the stability data, dramatically lower K48-linked ubiquitination of $\mathrm{Bcl}-3$ was observed in cells treated with Wnt3a than in control cells (Fig. 3c). As GSK-3 binds to and phosphorylates Bcl-3 at Ser394/398, which causes the degradation of $\mathrm{Bcl}-3$ by the ubiquitin-proteasome system, $^{34}$ we confirmed that the GSK-3 inhibitor SB216763 significantly increased Bcl-3 expression (Supplementary Fig. 3c). We then tested whether Wnt3a regulates the interaction and phosphorylation between GSK-3 and BCl-3. The immunoblot assay showed that $\mathrm{BCl}-3$ protein increased upon Wnt3a stimulation, while the Ser394/398 phosphorylation of $\mathrm{Bcl}-3$ decreased gradually (Fig. 3d, e). The immunoblot assay revealed that $\mathrm{Bcl}-3$ binds with GSK-3, and the interaction was dramatically decreased when the cells were treated with Wnt3a (Fig. 3f). These results thus indicate that Wnt3a stimulation interrupts the interaction between $\mathrm{BCl}-3$ and GSK-3, inhibits the phosphorylation of $\mathrm{BCl}-3$, and then shields $\mathrm{Bcl}-3$ from the ubiquitin-dependent proteasome degradation pathway.

As Wnt3a is known to stabilize $\beta$-catenin and increase its nuclear accumulation, we wanted to investigate and determine whether $\mathrm{Bcl}-3$ can be transported to the nucleus upon Wnt activation, similar to $\beta$-catenin. Indeed, $\mathrm{Bcl}-3$ and $\beta$-catenin were localized in both the cytoplasm and nucleus, and Wnt3a promoted the nuclear translocation of both proteins as determined by immunofluorescence (IF) analysis (Fig. 3g). As shown in Fig. 3h, Wnt3a significantly promoted the nuclear translocation of endogenous $\mathrm{BCl}-3$, as indicated by immunoblot analysis. In addition, neither the expression nor nuclear translocation of $\beta$-catenin changed when Bcl-3 was downregulated (Fig. 3h). Thus, the expression and nuclear translocation of $\beta$-catenin cannot be regulated by $\mathrm{BCl}-3$, although both proteins have some functional characteristics in common. These results suggest that Wnt3a increased the $\mathrm{Bcl}-3$ protein level and its nuclear translocation.

$\mathrm{Bcl}-3$ is required for $\beta$-catenin/TCF-mediated transcription and the expression of $\mathrm{Wnt} / \beta$-catenin target genes

Wnt activation-induced accumulation and nuclear translocation of $\beta$-catenin result in associations with members of the TCF/LEF family of DNA-bound transcription factors on TCF-binding elements to promote Wnt target gene expression. ${ }^{35,36}$ We used a TOP/Flash reporter to determine whether $\mathrm{Bcl}-3$ affects $\beta$-catenin-TCF-4/LEF transcriptional activity. Interestingly, Bcl-3 KD strongly inhibited TOP/Flash reporter expression in the HCT116 cell line with or without Wnt3a treatment (Fig. 4a). The same result was confirmed in other CRC cell lines, SW620 and SW480, which have high levels of endogenous $\beta$-catenin (Fig. 4a). We also confirmed this result with the Dox-induced 
a
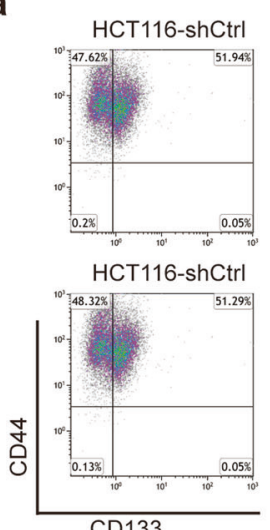

CD133

b
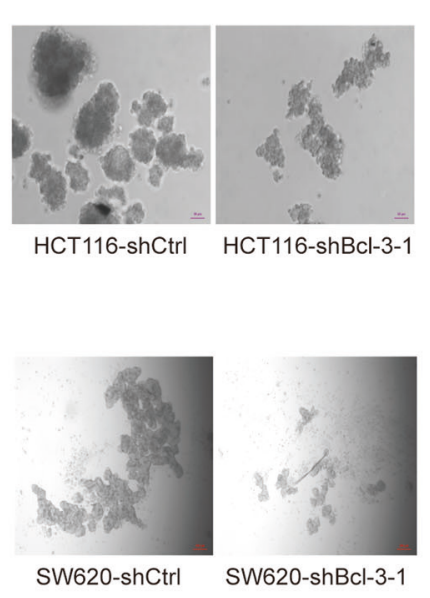

d

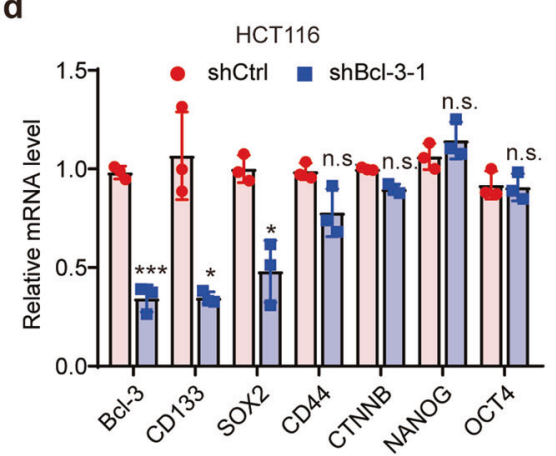

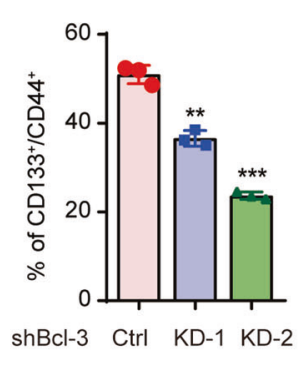

shBcl-3 Ctrl KD-1 KD-2
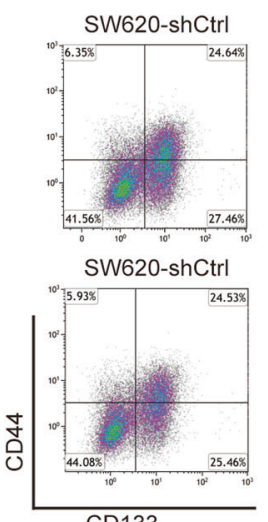

CD133

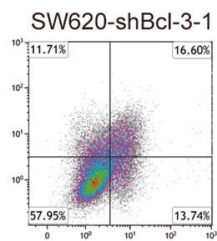

SW620-shBcl-3-2
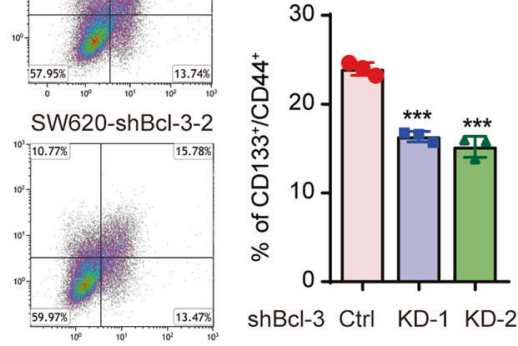

shBcl-3 Ctrl KD-1 KD-2

C
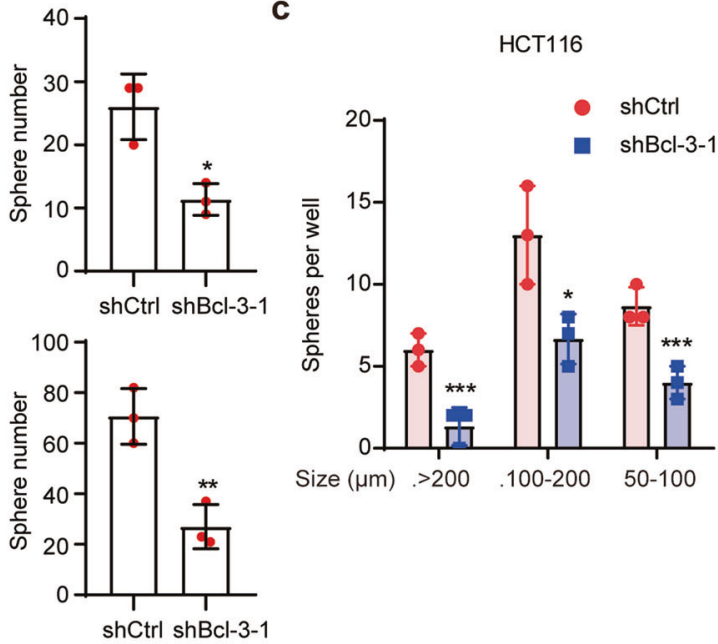

SW620

e
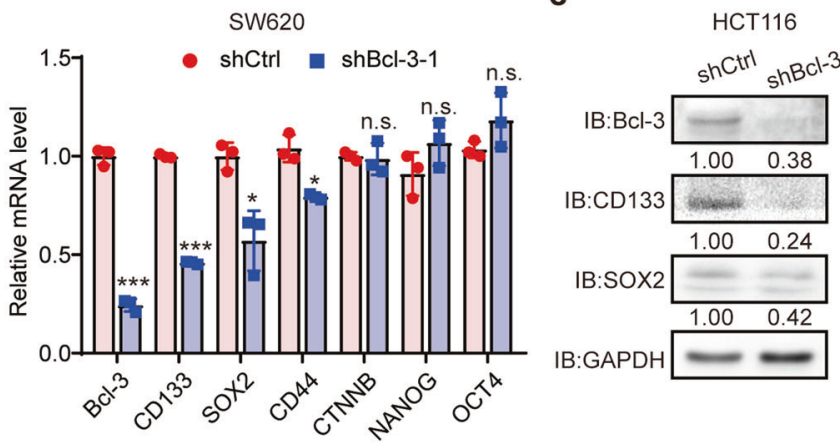

SW620

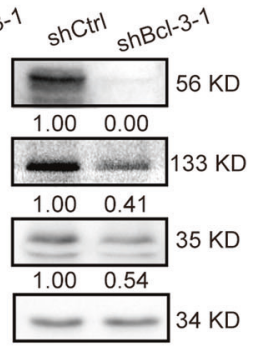

Fig. $1 \mathrm{BCl}-3$ maintains stem cell-like properties in $\mathrm{CRC}$ cells in vitro. a CD133 ${ }^{+} \mathrm{CD} 44^{+}$subpopulations were detected in Bcl-3-depleted HCT116 and SW620 cells by FACS analyses, and plotted as the percentage of positive cells. The results are shown as the means \pm SD. ${ }^{*} p<0.05,{ }^{* *} p<$ 0.01 , and ${ }^{* * *} p<0.001$ by two-tailed Student's $t$-test. b Bcl-3 depletion causes a reduced sphere-forming capacity in the CRC cell lines HCT116 and SW620. The left panel shows representative images, and the right panel represents the number of spheres formed by the indicated cells. ${ }^{*} p<0.05,{ }^{* *} p<0.01$, and ${ }^{* * *} p<0.001$ by two-tailed Student's $t$-test. $\mathbf{c}$ The size of spheres derived from the indicated cells in $\mathbf{b}$. ${ }^{*} p<0.05$, ${ }^{* *} p<$ 0.01 , and ${ }^{* * *} p<0.001$ by two-tailed Student's $t$-test. d q-RT-PCR analysis of the expression level of CSC-related genes (CD133, SOX2, CD44, CTNNB1, NANOG, and OCT4) and BCl-3 in Bcl-3-silenced cells compared with control cells. The results are expressed as the means \pm SD for each cohort $(n=3) .{ }^{*} p<0.05,{ }^{* *} p<0.01$, and ${ }^{* * *} p<0.001$ by two-tailed Student's $t$-test. e Immunoblots for BCl-3, CD133, and SOX2 in HCT116 and SW620 cells

Tet-on shRNA system in SW480 and LOVO cells (Fig. 4b). Moreover, overexpression of $\mathrm{Bcl}-3$ alone significantly activated the TOP/Flash reporter in SW480 cells (Fig. 4d). In the HEK293T cell line, the activation of the TOP/Flash reporter could only be induced after Wnt3a treatment when $\mathrm{Bcl}-3$ was overexpressed (Fig. 4c); a possible explanation may be that HEK293T cells have barely detectable endogenous $\beta$-catenin activation in the absence of Wnt3a stimulation, which suggests that $\mathrm{Bcl}-3$ mediated $\beta$-catenin-TCF-4 transcriptional activity should be initiated by Wnt activation.

Next, we examined the expression of several Wnt/ $\beta$-catenin target genes in Bcl-3-silenced cell lines. The mRNA levels of AXIN2 and $\mathrm{ZCCHC12}$ were decreased in $\mathrm{HCT} 116$ cells with $\mathrm{BCl}-3 \mathrm{KD}$ (Fig. 4e). Moreover, the expression of Axin2, c-jun, and Tcf-7 was 
a

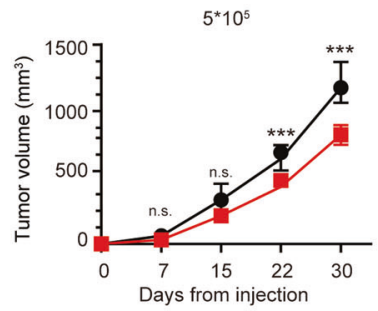

b

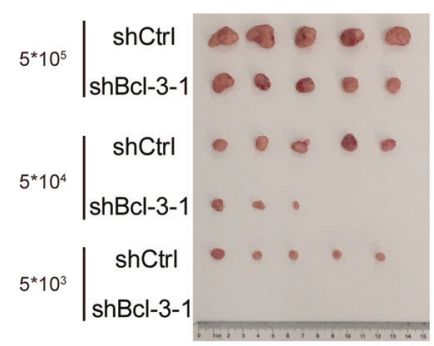

d
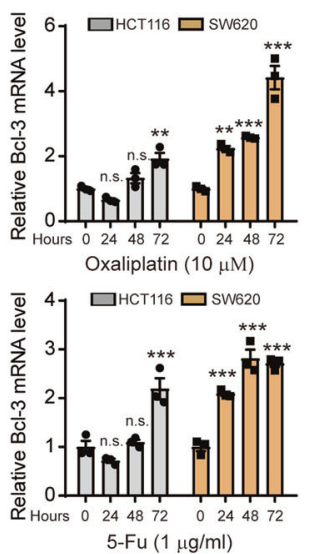

g

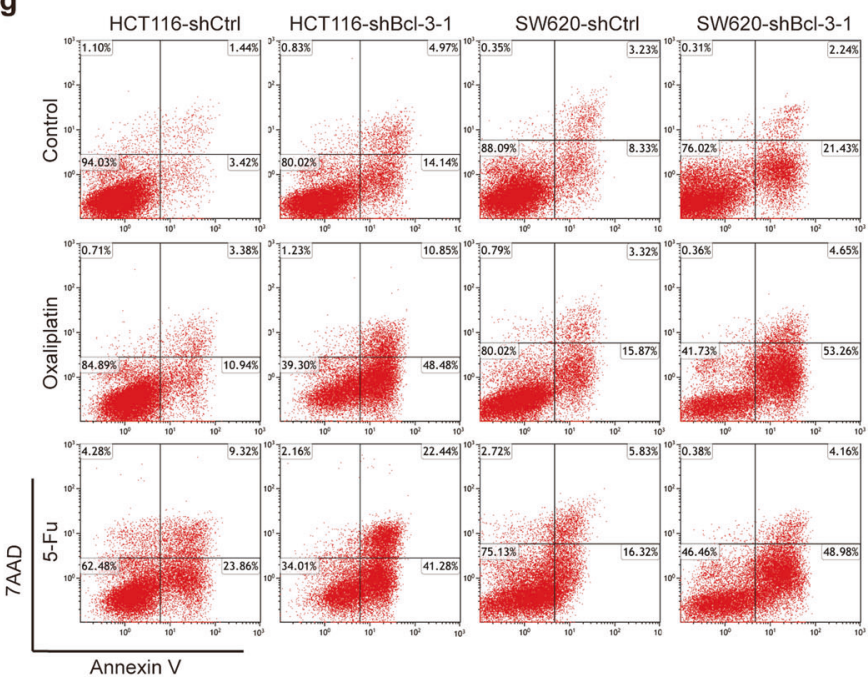

c

\begin{tabular}{|c|c|c|}
\hline \multirow{2}{*}{ Cell number } & \multicolumn{2}{|c|}{ Incidence (\%) } \\
\cline { 2 - 3 } & WT & KD \\
\hline $5^{*} 10^{5}$ & $5 / 5$ & $5 / 5$ \\
\hline $5^{*} 10^{4}$ & $5 / 5$ & $3 / 5$ \\
\hline $5^{*} 10^{3}$ & $5 / 5$ & $0 / 5$ \\
\hline TIF $(95 \% \mathrm{CI})$ & $1 / 5448$ & $1 / 63097$ \\
\hline & \multicolumn{2}{|c|}{$p=0.00262$} \\
\hline
\end{tabular}

TIF: Tumor Initiating Frequency

e

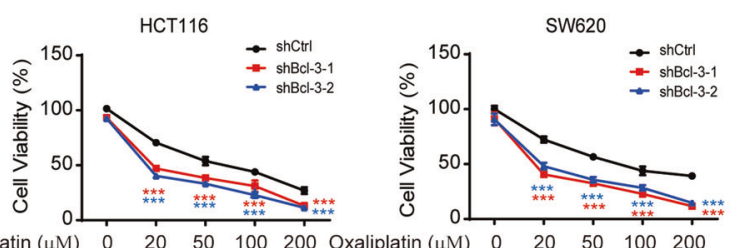

f
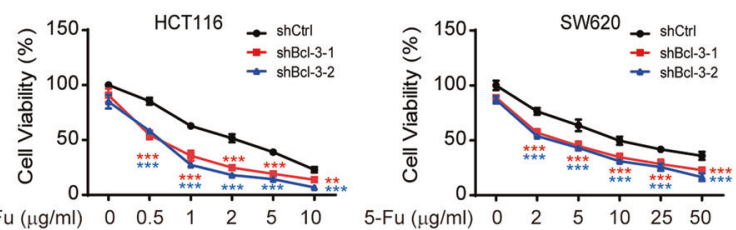

h

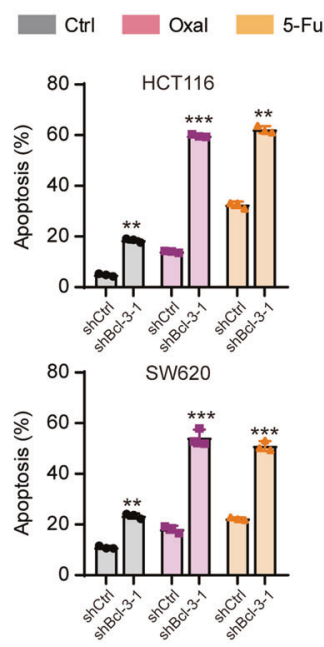

Fig. $2 \mathrm{BCl}-3$ enhances the tumorigenicity and chemoresistance of $\mathrm{CRC}$ in vivo. a A total of $5 \times 10^{5}, 5 \times 10^{4}$, and $5 \times 10^{3} \mathrm{Bcl}-3$-silenced (shBcl-3KD-1) HCT116 cells or control cells were subcutaneously inoculated into BALB/c nude mice for observation of tumor growth. The results are shown as the means $\pm \mathrm{SD}$; $\left(n=5\right.$ for each group). *Adjusted $p$ value $<0.05 ;{ }^{* *}$ adjusted $p$ value $<0.01$; and ${ }^{* * *}$ adjusted $p$ value $<0.001$ by twoway ANOVA. b Representative images of tumors in a, 30 days after injection. c Tumorigenic cell frequency in Bcl-3-silenced HCT116 cells or control cells was determined by limiting dilution assays (http://bioinf.wehi.edu.au/software/elda/). d q-RT-PCR analysis of BCl-3 mRNA expression levels in HCT116 and SW620 cells treated with 5-FU and oxaliplatin for the indicated time points. ${ }^{*}$ Adjusted $p$ value $<0.05$; ${ }^{* *}$ adjusted $p$ value $<0.01$; and ***adjusted $p$ value $<0.001$ by one-way ANOVA. e, $\mathbf{f ~ B C l - 3 - K D ~ a n d ~ c o r r e s p o n d i n g ~ c o n t r o l ~ c e l l s ~ w e r e ~ t r e a t e d ~ w i t h ~}$ different concentrations of 5-FU or oxaliplatin for $48 \mathrm{~h}$. Cell viability was determined by MTT assay. ${ }^{*}$ Adjusted $p$ value $<0.05$; ${ }^{* *}$ adjusted $p$ value $<0.01$; and ***adjusted $p$ value $<0.001$ by two-way ANOVA. $\mathbf{g}, \mathbf{h ~ B c l - 3 - s i l e n c e d ~ c e l l s ~ a n d ~ c o n t r o l ~ c e l l s ~ w e r e ~ t r e a t e d ~ w i t h ~} 5$-FU ( $1 \mu \mathrm{g} / \mathrm{ml}$ ) or oxaliplatin $(20 \mu \mathrm{M})$ for $48 \mathrm{~h}$ as indicated. The percentage of apoptotic cells was determined by flow cytometry 
a

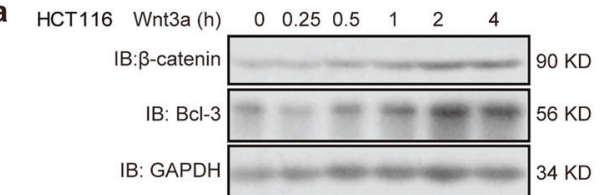

293T Wnt3a (h) $\quad \begin{array}{lllllll}0 & 1 & 2 & 3 & 4 & 5\end{array}$

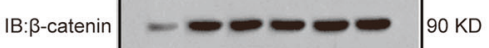

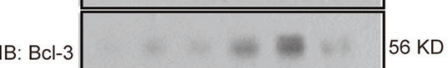

IB: GAPDH

b

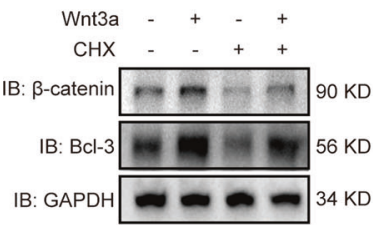

d

Wnt3a (h) $\quad 0 \quad 1 \quad 2 \quad 3 \quad 3 \quad 4 \quad 5$

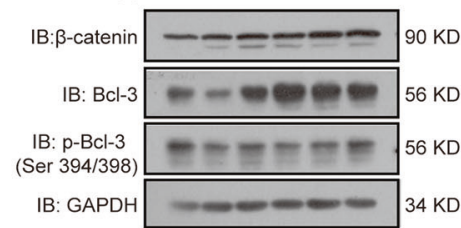

e
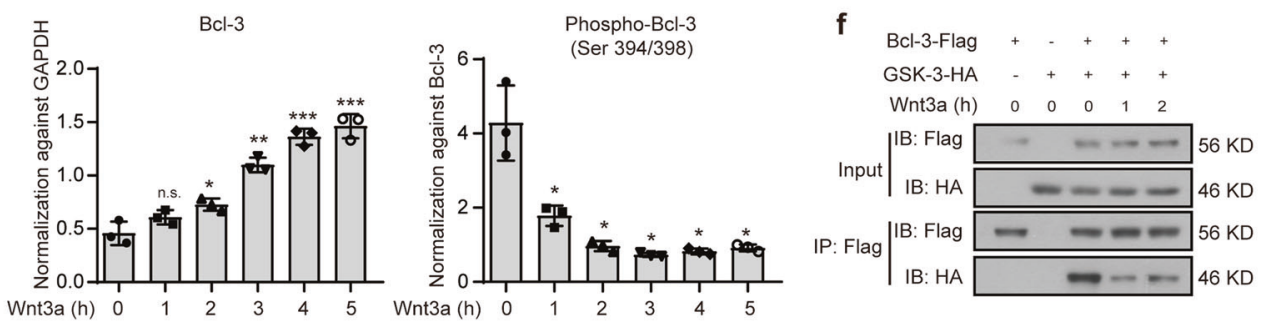

9

Bcl-3
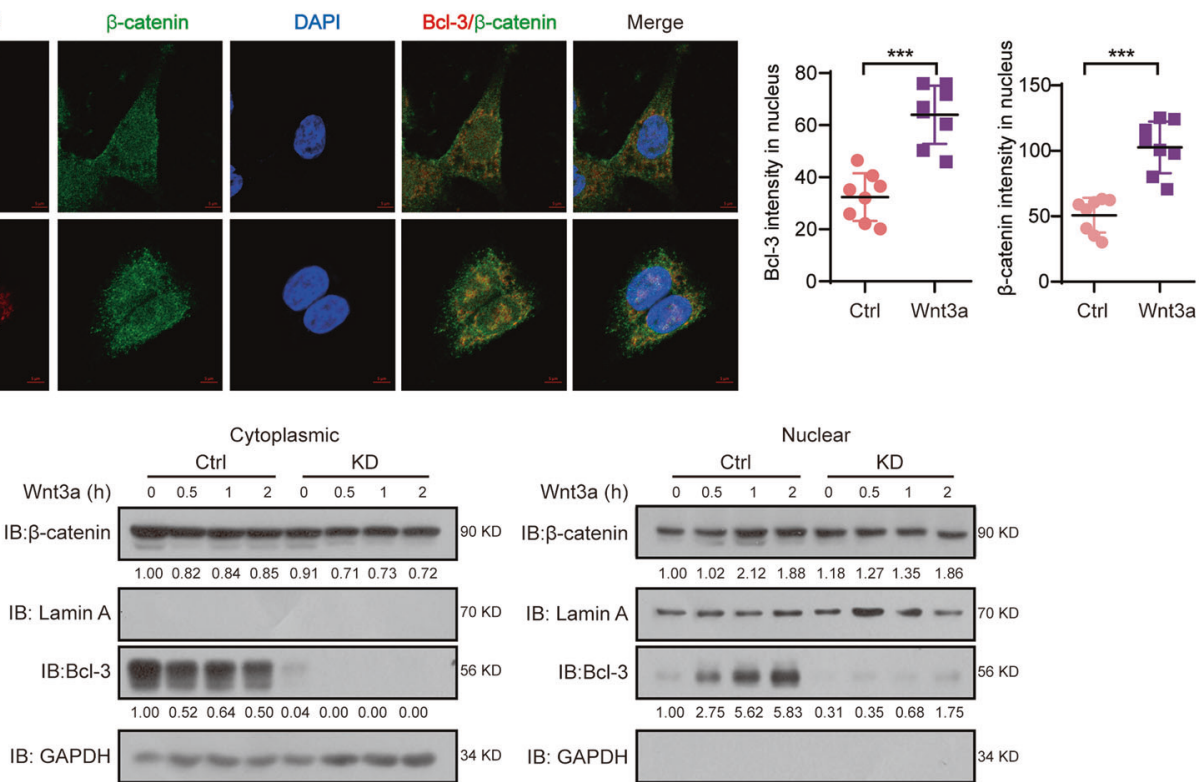

Fig. 3 The Wnt3a-induced increase in Bcl-3 protein relies on GSK-3 kinase activity. a Immunoblot for Bcl-3 and $\beta$-catenin in $\mathrm{HCT} 116$ and $293 \mathrm{~T}$ cells treated with $100 \mathrm{ng} / \mathrm{ml} \mathrm{Wnt3a}$ for the indicated times (left). q-RT-PCR analysis of Bcl-3 mRNA expression levels in HCT116 and $293 \mathrm{~T}$ cells treated with $100 \mathrm{ng} / \mathrm{ml} \mathrm{Wnt3a}$ for the indicated time points (right). b HCT116 cells were treated with cycloheximide (CHX, 50 mg/

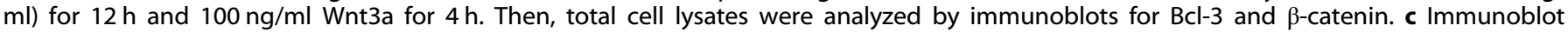
analyses of immunoprecipitated Bcl-3 for the presence of K48- and K63-linked ubiquitin after MG-132 and Wnt3a stimulation. * Represents the heavy chain band. d Immunoblot analyses of Bcl-3, p-Bcl-3 (Ser394/398), and $\beta$-catenin after Wnt3a stimulation for the indicated time points. e The normalized Bcl-3 and p-Bcl-3 (Ser394/398) protein levels detected in d. f Co-IP analyses of Flag-tagged Bcl-3 (Bcl-3-Flag) and HA-tagged GSK-3 (GSK-3-HA) expressed in 293 T cells. After treatment with Wnt3a for the indicated times, cell lysates were subjected to IP with anti-Flag antibody. $\mathbf{g}$ Immunofluorescence staining of $\mathrm{BCl}-3$ (red) and $\beta$-catenin (green) in HCT116 cells with or without Wnt3a stimulation for 2 h. The nuclei were stained using DAPI (blue). ImageJ software was used to quantify the results. $\mathbf{h}$ Cytoplasmic and nuclear levels of Bcl-3 and

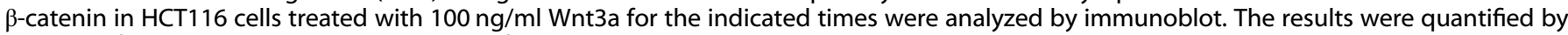
ImageJ software. The relative protein levels of $\beta$-catenin and $\mathrm{Bcl}-3$ in the cytoplasm were normalized to GAPDH levels, and the relative protein levels of these two proteins in the nucleus were normalized to Lamin A levels 
a

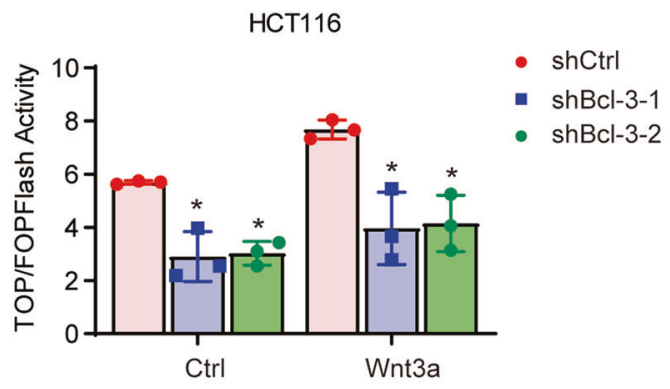

SW620

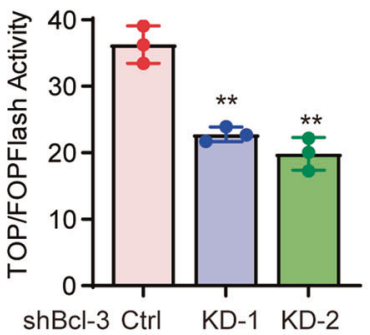

C

b

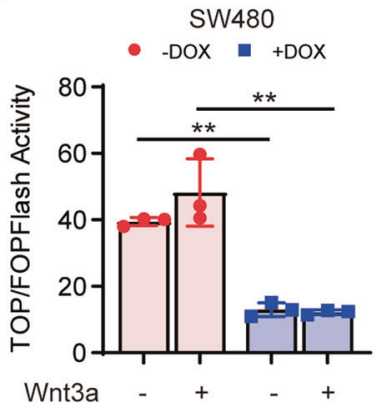

e

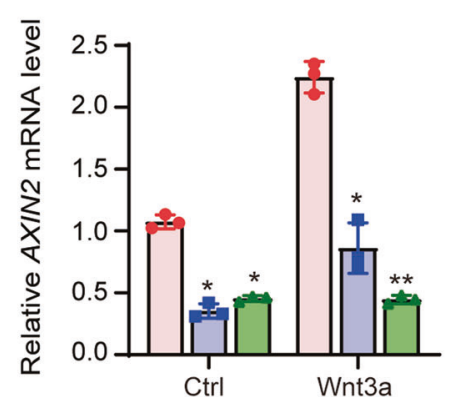

f

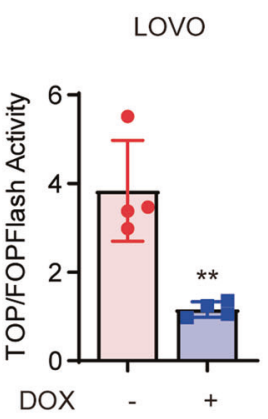

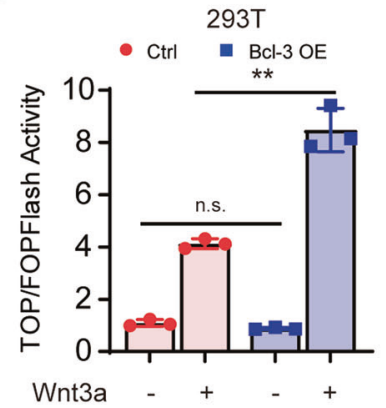

shCtrl $\square$ shBcl-3-1 $\quad$ shBcl-3-2

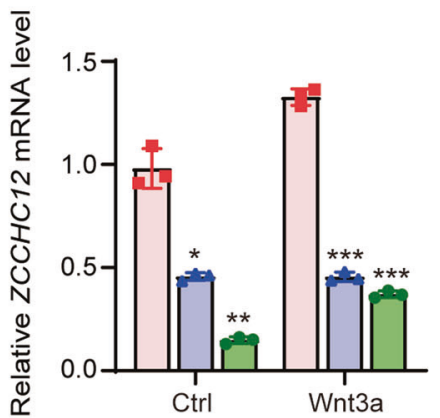

SW480

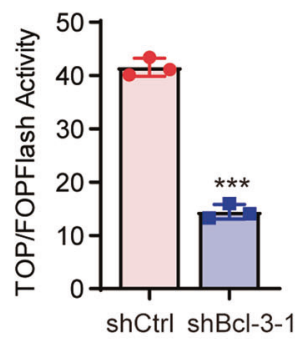

d

SW480

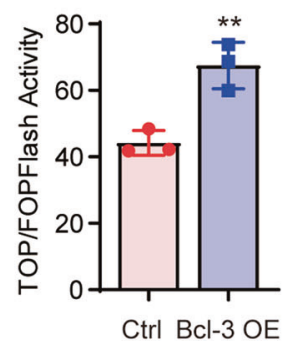

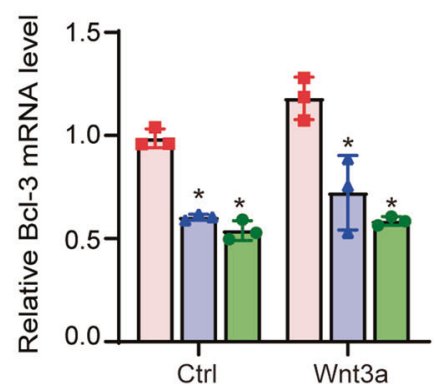

WT

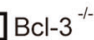
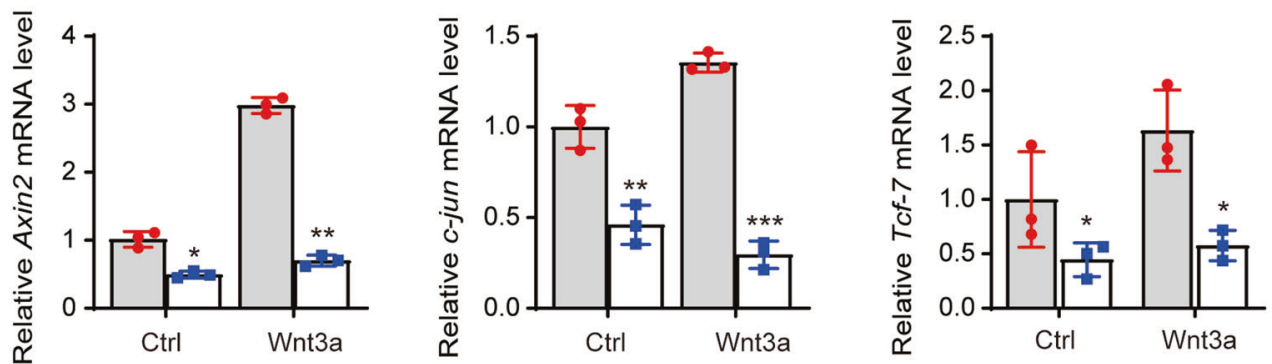

Fig. $4 \mathrm{BCl}-3$ is required for $\beta$-catenin/TCF-4-mediated transcription and the expression of Wnt/ $\beta$-catenin target genes. a HCT116 and SW620 cells with two different shRNA sequences and SW480 cells with the shBcl-3 KD-1 sequence were cotransfected with TOP/Flash or FOP/Flash reporter and Renilla luciferase normalization control. After Wnt3a treatment for $24 \mathrm{~h}$ or not, total cell lysate was collected to measure the firefly and Renilla luciferase activities. b SW480 and LOVO cells with a doxycycline (Dox, $1 \mu \mathrm{g} / \mathrm{ml}$ )-inducible Tet-on KD system were used. c, d Cells were cotransfected with Bcl-3-Flag or control expression plasmid with TOP/Flash or FOP/Flash reporter, and Renilla luciferase normalization control. After Wnt3a treatment for $24 \mathrm{~h}$ or not, total cell lysate was collected to measure the firefly and Renilla luciferase activities. Values are the means \pm SD for each cohort $(n=3) .{ }^{*} p<0.05$ and ${ }^{* *} p<0.01$ by two-tailed Student's $t$-test. e AXIN2, ZCCHC12, and BCl-3 mRNA expression levels were detected in Bcl-3 KD HCT116 cells with or without Wnt3a treatment for $24 \mathrm{~h}$. $\mathbf{f}$ Axin2, c-jun, and Tcf-7 mRNA expression levels were detected in wild-type and Bcl-3 knockout MEFs with or without Wnt3a treatment for $24 \mathrm{~h}$. The results are shown as the means \pm SD. ${ }^{*} p<0.05$, ${ }^{* *} p<0.01$, and ${ }^{* * *} p<0.001$ by two-tailed Student's $t$-test 
downregulated, and could not be induced after Wnt activation in $\mathrm{Bcl}-3$ knockout MEFs (Fig. 4f). Together, these results indicate that $\mathrm{BCl}-3$ is required for $\beta$-catenin/TCF-mediated transcription and the expression of $\mathrm{Wnt} / \beta$-catenin target genes.

$\mathrm{Bcl}-3$ interacts with $\beta$-catenin and is required for $\beta$-catenin recruitment to Wnt target gene promoters

The IF analysis above showed that endogenous $\mathrm{Bcl}-3$ and $\beta$-catenin were colocalized in both the cytoplasm and nucleus, regardless of Wnt3a stimulation (Fig. 3g). Then, we confirmed the interaction by immunoprecipitation (IP) analysis. In the HCT116 cell line, co-IP assays demonstrated that endogenous Bcl-3 bound to endogenous $\beta$-catenin (Fig. $5 \mathrm{a}$ ). In addition, we cotransfected vectors encoding Flag-tagged $\mathrm{Bcl}-3, \mathrm{HA}$-tagged $\beta$-catenin (WT), or an $\mathrm{N}$-terminal deletion mutant of $\beta$-catenin ( $\mathrm{dN} 89$, transcriptionally active form of $\beta$-catenin lacking the $\mathrm{N}$-terminal 89 amino acids ${ }^{37}$ ) into HEK293T cells, followed by IP of the cell lysates with an antibody against the HA tag. Immunoblot assays revealed that both WT and dN89 $\beta$-catenin could bind to Bcl-3 (Fig. 5b). Further mapping analysis revealed that an $\mathrm{N}$-terminal deletion mutant of $\mathrm{Bcl}-3$ (dN125, a mutant form of Bcl-3 lacking the N-terminal 125 amino acids) could not interact with $\beta$-catenin, while dN30 (a mutant form of $\mathrm{Bcl}-3$ lacking the $\mathrm{N}$-terminal 30 amino acids) $\mathrm{Bcl}-3$ could still be found in the $\beta$-catenin complex (Fig. $5 \mathrm{~d}$ ). To ascertain whether $\mathrm{Bcl}-3$ mutants affect the transcriptional activity of Wnt/ $\beta$-catenin signaling, Bcl-3 full-length and mutant constructs were cotransfected with TOP/FOP Flash luciferase reporter vectors into $293 \mathrm{~T}$ cells. Consistent with the mapping assay (Fig. 5d), overexpression of full-length Bcl-3 and dC116 (a mutant form of $\mathrm{BCl}-3$ lacking the C-terminal 116 amino acids) mutants strongly activated TOP/Flash reporter activity, whereas dN125 and $\mathrm{dNC}$ did not (Fig. 5e). Thus, these results indicate that $\mathrm{Bcl}-3$ interacts with $\beta$-catenin and that the capability of $\mathrm{BCl}-3$ to promote $W n t / \beta$-catenin transcriptional activity correlates with the a

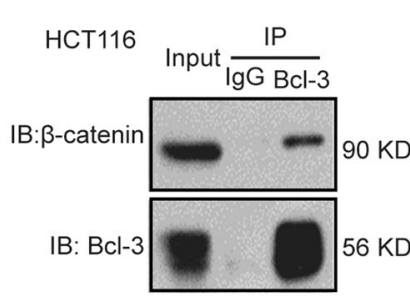

b

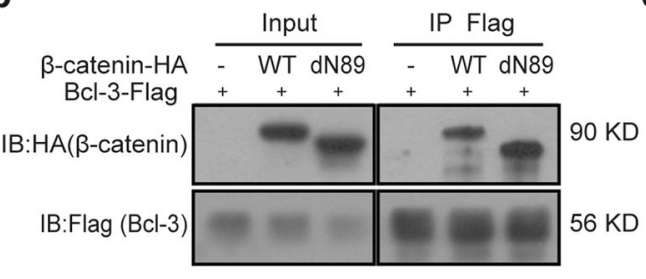

C

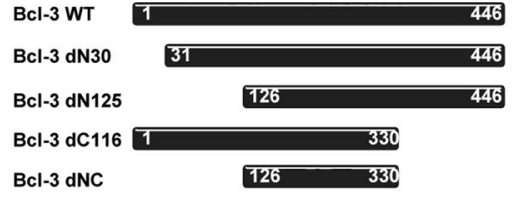

d

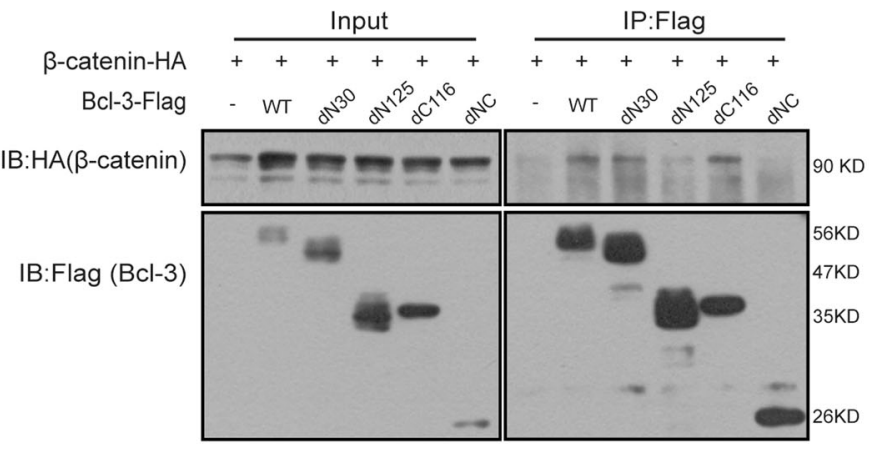

$\mathbf{f}$

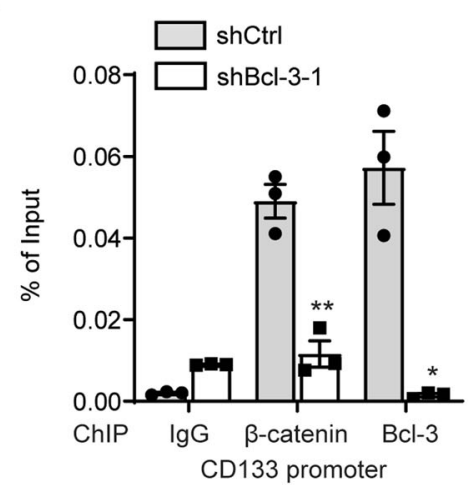

g

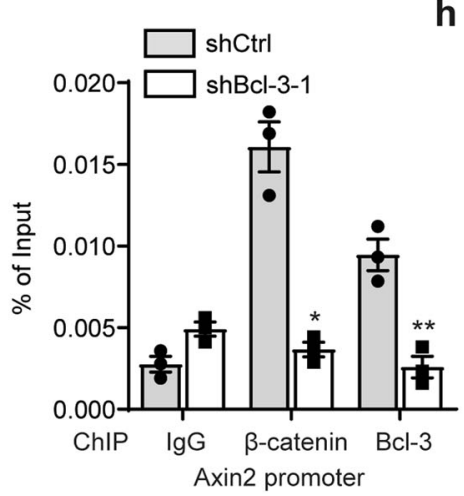

h e
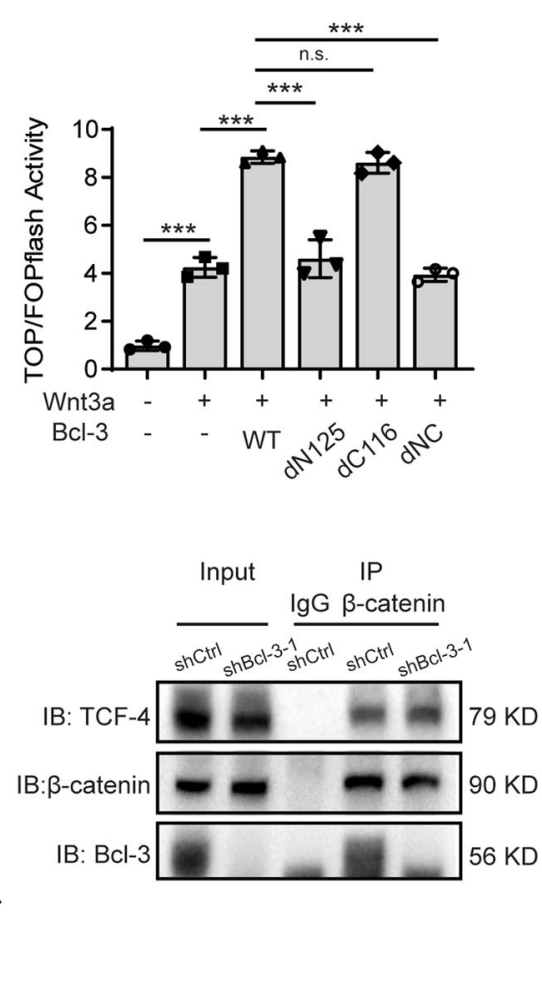

Fig. $5 \mathrm{Bcl}-3$ interacts with $\beta$-catenin and is required for $\beta$-catenin recruitment to Wnt target gene promoters. a HCT116 cell lysates were prepared, and anti-Bcl-3 antibody was used in IP followed by immunoblot using the indicated antibodies. b Co-IP analyses of Bcl-3-Flag and $\beta$-catenin truncated expression vectors (HA-tagged $\beta$-catenin (WT) or N-terminal 89 amino acid deletion mutant of $\beta$-catenin) in 293 T cells and cell lysates with anti-Flag antibodies. $\mathbf{c}$ Representation of the wild-type Bcl-3 protein and Bcl-3 mutants. $\mathbf{d}$ Co-IP analyses of $\beta$-catenin-HA and Bcl-3-truncated expression vectors (WT: 1-446 amino acids; dN30: 31-446 amino acids; dN125: 126-446 amino acids; dC116: 1-330 amino acids, and dNC: 126-330 amino acids) in HEK293T cells, and cell lysates were immunoprecipitated with anti-Flag antibodies. e 293T cells were cotransfected with the indicated plasmids and TOP/Flash or FOP/Flash reporter plasmid, treated with Wnt3a for $24 \mathrm{~h}$, and total cell lysates were collected to measure the firefly and Renilla luciferase activities. Values are means \pm SD for each cohort $(n=3)$. ${ }^{* * *} p<0.001$ by two-tailed Student's t-test. f, $\mathbf{g}$ ChIP assays on the promoter regions of the CD133 and AXIN2 genes were performed in control and Bcl-3-silenced HCT116 cells. $\mathbf{h}$ Co-IP analyses of the $\beta$-catenin and TCF-4 interaction in control and Bcl-3-silenced HCT116 cells 
a

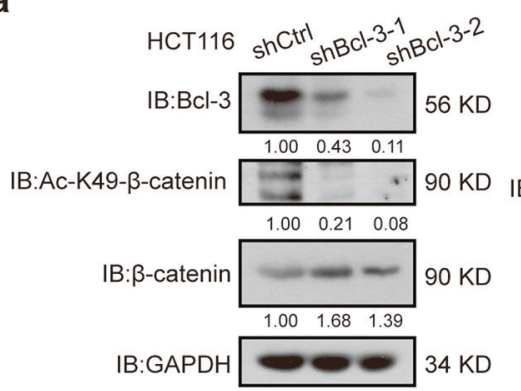

b

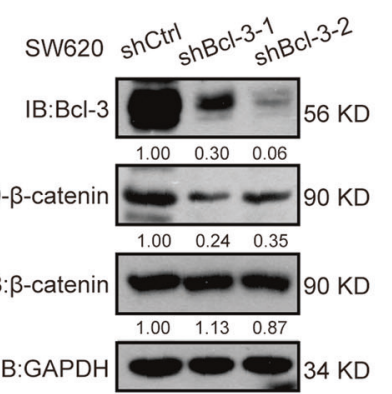

C

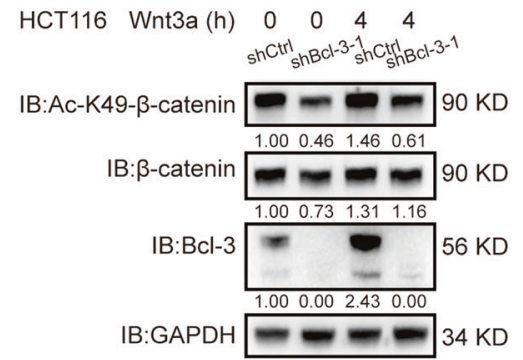

d

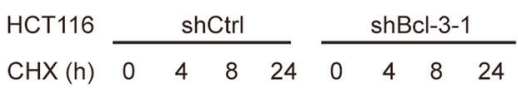

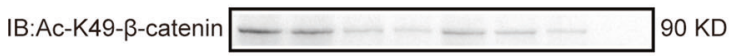

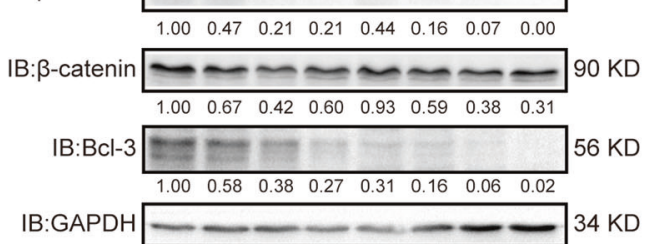

f

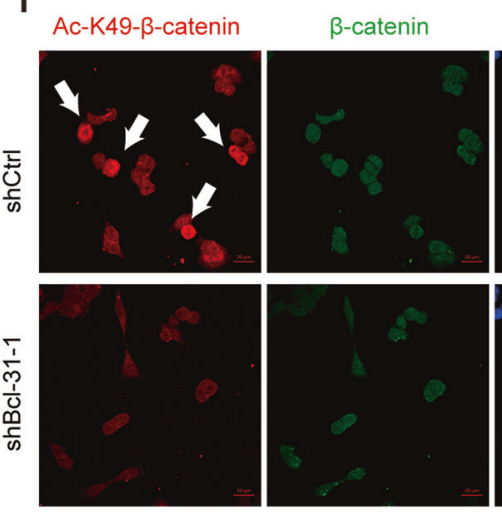

$\mathbf{h}$
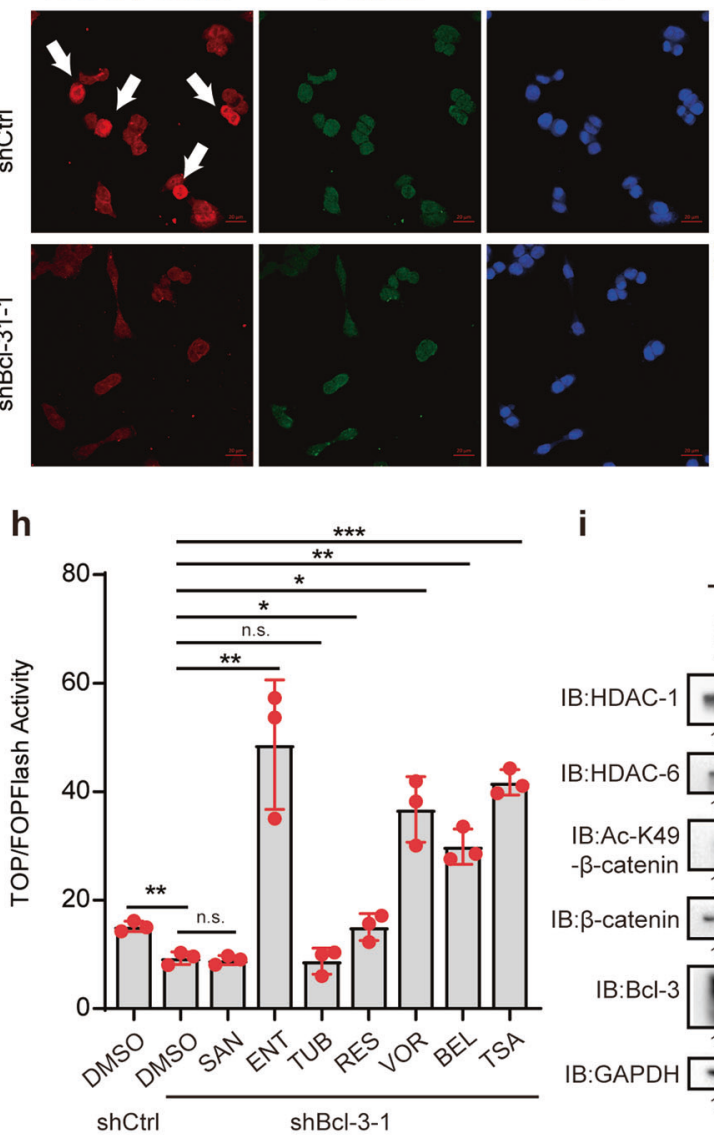

i e

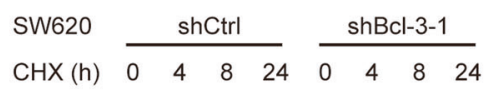

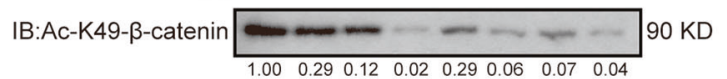

IB:ß-catenin 90 KD

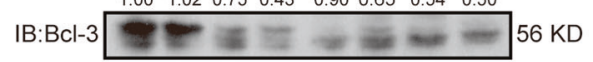

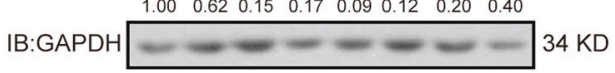

g
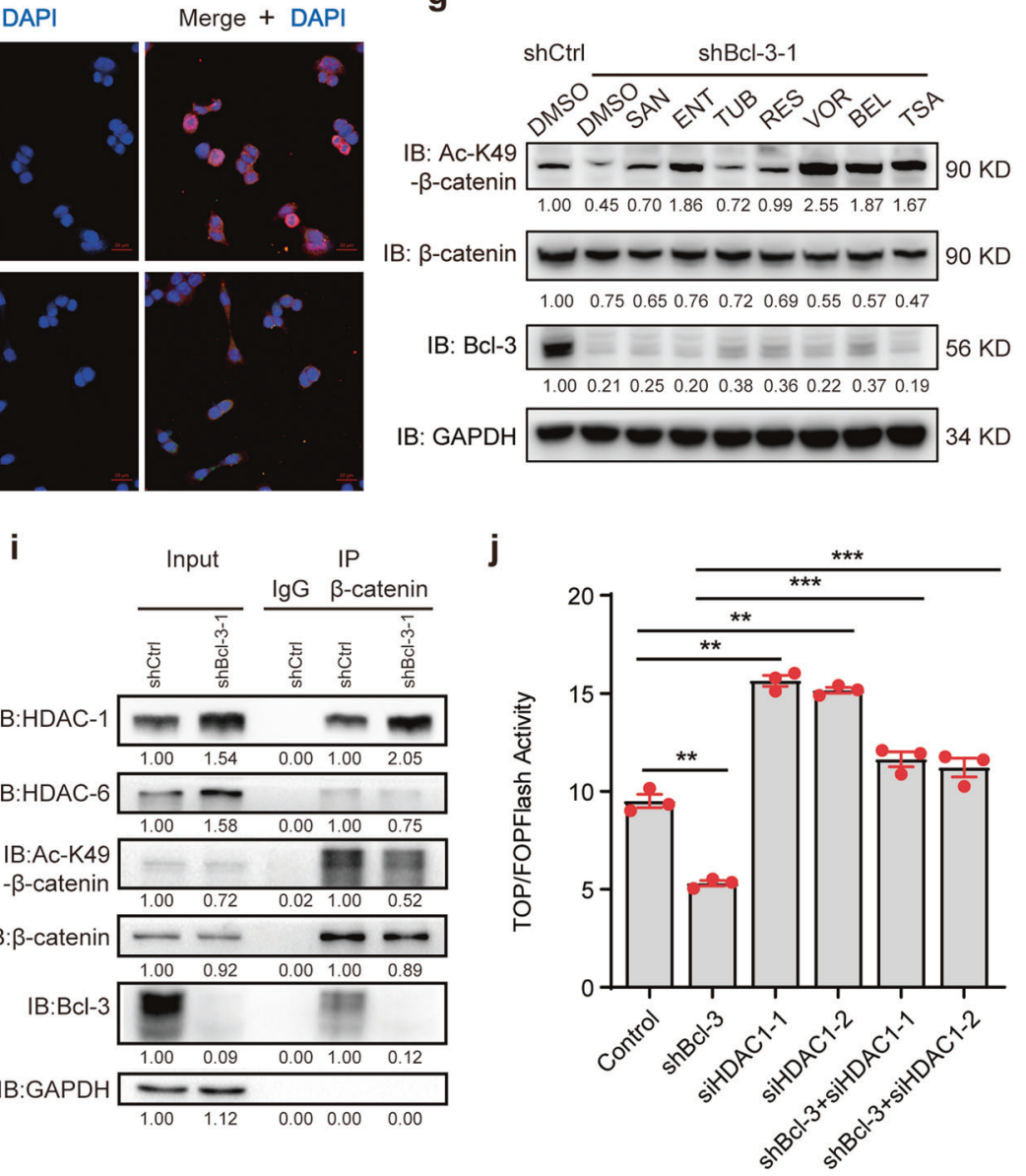

binding of $\mathrm{Bcl}-3$ and $\beta$-catenin. The chromatin immunoprecipitation (ChIP) assay was then performed in HCT116 cells, and we found that both $\mathrm{BCl}-3$ and $\beta$-catenin were recruited to the endogenous promoters of the CD133 and Axin2 genes (Fig. 5f, g). The association of $\beta$-catenin with gene promoters decreased upon Bcl-3 depletion (Fig. 5f, g). However, the co-IP analysis results indicated that $\mathrm{BCl}-3$ depletion did not influence the interaction of $\beta$-catenin and TCF-4 (Fig. 5h), which suggested that the target factor influenced by $\mathrm{Bcl}-3$ might be $\beta$-catenin. Thus, these results show that $\mathrm{BCl}-3$ can form a complex with $\beta$-catenin to activate Wnt target gene expression by binding with gene promoters. 
Fig. $6 \mathrm{Bcl}-3$ promotes Wnt signaling by regulating the K49 acetylation of $\beta$-catenin. $\mathbf{a}, \mathbf{b}$ Immunoblot analyses of $\mathrm{Bcl}-3$, Ac-K49- $\beta$-catenin, and $\beta$-catenin in control and Bcl-3-silenced HCT116 cells a and SW620 cells $\mathbf{b}$. c Immunoblot analyses of Bcl-3, Ac-K49- $\beta$-catenin, and $\beta$-catenin in control and Bcl-3-silenced HCT116 cells treated with Wnt3a for $4 \mathrm{~h}(100 \mathrm{ng} / \mathrm{ml})$. d, e Immunoblot analyses of Bcl-3, Ac-K49- $\beta$-catenin, and $\beta$-catenin in control, and Bcl-3-silenced HCT116 cells and SW620 cells treated with CHX for the indicated time points. f Immunofluorescence staining of Ac-K49- $\beta$-catenin (red) and $\beta$-catenin (green) in control, and Bcl-3-silenced HCT116 cells. The nuclei were stained using DAPI (blue). g Immunoblot analyses of BCl-3, Ac-K49- $\beta$-catenin, and $\beta$-catenin in control, and Bcl-3-silenced HCT116 cells treated with or without different HDAC inhibitors for $24 \mathrm{~h}$; (SAN, santacruzamate $A, 1 \mu \mathrm{M}$; ENT, entinostat, $5 \mu \mathrm{M}$; TUB, tubacin, $5 \mu \mathrm{M}$; RES, resminostat, $1 \mu \mathrm{M}$; VOR, vorinostat, $10 \mu \mathrm{M} ; \mathrm{BEL}$, belinostat, $1 \mu \mathrm{M}$; and TSA, $1 \mu \mathrm{M})$. h Control and Bcl-3-silenced HCT116 cells were cotransfected with TOP/Flash or FOP/Flash reporter and Renilla luciferase normalization control. After HDAC inhibitor treatment for $24 \mathrm{~h}$, total cell lysate was collected to measure the firefly and Renilla luciferase activities. Values are means \pm SD for each cohort $(n=3)$. i Lysates from control and Bcl-3-silenced HCT116 cells were prepared, and anti- $\beta$-catenin antibody was used in IP followed by immunoblot using the indicated antibodies. The results were quantified by ImageJ software. The relative protein levels in the input group were normalized to GAPDH levels. The relative protein levels in the IP group were normalized to $\beta$-catenin levels. $\mathbf{j}$ HCT116 cells were cotransfected with the indicated siRNA and TOP/Flash or FOP/Flash reporter plasmid, and then total cell lysates were collected to measure the firefly and Renilla luciferase activities. Values are means \pm SD for each cohort $(n=3) .{ }^{*} p<0.05,{ }^{* *} p<0.01$, and ${ }^{* * *} p<0.001$ by two-tailed Student's $t$-test

$\mathrm{Bcl}-3$ promotes Wnt signaling by regulating the K49 acetylation of B-catenin

As $\mathrm{Bcl}-3$ did not affect the expression of $\beta$-catenin, we diverted our attention to the epigenetic modification of $\beta$-catenin. Since $\beta$-catenin can be acetylated at K49 by CREB-binding protein (CBP) and Ac-K49 $\beta$-catenin is required for activation of Wnt target genes, $^{38-40}$ we detected the Ac-K49 $\beta$-catenin level when BCl-3 was silenced. Notably, Bcl-3 depletion significantly decreased AcK49 $\beta$-catenin in both HCT116 and SW620 cells (Fig. 6a, b). The same results were observed in HCT116 cells treated with Wnt3a (Fig. 6c). When de novo protein synthesis was inhibited by $\mathrm{CHX}$, the degradation of Ac-K49 $\beta$-catenin was remarkably faster in $\mathrm{BCl}$ 3 -silenced cells than in control cells (Fig. $6 \mathrm{~d}$, e). Similarly, the KD of $\mathrm{BCl}-3$ substantially decreased the level of Ac-K49 $\beta$-catenin, as determined by IF analysis (Fig. 6f). Moreover, CBP overexpression in $\mathrm{BCl}-3 \mathrm{KD}$ cells significantly increased the Wnt/ $\beta$-catenin transcriptional activity (Supplementary Fig. 4a).

The small molecule ICG-001 inhibits the Wnt/ $\beta$-catenin signaling pathway by first disrupting the interaction between CBP and $\beta$-catenin, and then decreasing the Ac-K49 $\beta$-catenin level. ${ }^{41}$ As shown in Supplementary Fig. 4b, ICG-001 treatment resulted in dramatically lower reporter activity, regardless of $\mathrm{Bcl}-3$ overexpression (Supplementary Fig. 4b). Then, q-RT-PCR analysis of the CD133 and SOX2 genes indicated the same effect of ICG-001 on endogenous target gene expression (Supplementary Fig. 4c). The number of spheres in ICG-001-treated HCT116 cells was found to be $>2$-fold less than the number of spheres formed in DMSOtreated cells (Supplementary Fig. 4d).

Next, we examined how $\mathrm{Bcl}-3$ regulates the expression of AcK49 $\beta$-catenin. First, we blocked ubiquitin-mediated proteasome activity by treating cells with MG-132 and a lysosome-mediated degradation system with chloroquine, followed by detecting AcK49 $\beta$-catenin levels. Surprisingly, the protein level of Ac-K49 $\beta$-catenin increased after MG-132 treatment of control cells but barely increased in Bcl-3-silenced cells. Moreover, Ac-K49 $\beta$-catenin was not changed in control cells or Bcl-3-silenced cells after chloroquine stimulation (Supplementary Fig. 4e).

We have shown that the inhibitor of Ac-K49 $\beta$-catenin ICG-001 could mimic the effect of $\mathrm{BCl}-3 \mathrm{KD}$ on the $\mathrm{Wnt} / \beta$-catenin signaling pathway. Then, we considered the deacetylation modification of $\beta$-catenin. We used two inhibitors of histone deacetylase, tubastatin A (TSA, which inhibits HDACs) and niacinamide (NAM, which specifically inhibits SITRs), and analyzed the protein level of Ac-K49 $\beta$-catenin in $\mathrm{BCl}-3 \mathrm{KD}$ and control cells. As shown in Supplementary Fig. 4f, both NAM and TSA induced Ac-K49 $\beta$-catenin levels in control cells, and only TSA rescued the Ac-K49 $\beta$-catenin levels when $\mathrm{Bcl}-3$ was knocked down. Then, we verified the effect of other HDAC inhibitors on Ac-K49 $\beta$-catenin levels in $\mathrm{Bcl}$-3-depleted cells. Vorinostat and belinostat are two inhibitors targeting HDACs; resminostat inhibits HDAC-1, -3, and -6 ; entinostat inhibits HDAC- 1 and -3 ; santacruzamate $A$ inhibits HDAC-2; and tubacin is an inhibitor of HDAC-6. We treated the indicated cells with or without these inhibitors for $24 \mathrm{~h}$ and detected the expression of related proteins. The western blot assay indicated that an inhibitor of HDAC -1 and -3 (entinostat), an inhibitor of HDAC-1, -3 , and -6 (resminostat), and three inhibitors of HDACs (vorinostat, belinostat, and TSA) could rescue the expression of Ac-K49 $\beta$-catenin when $\mathrm{Bcl}-3$ was knocked down (Fig. 6g). Additionally, treatment with these five inhibitors significantly enhanced Wnt/ $\beta$-catenin transcriptional activity in Bcl-3-silenced cells (Fig. 6h). The mRNA level of CD133 decreased in $\mathrm{BCl}-3 \mathrm{KD}$ cells, and it was upregulated after treatment with these five inhibitors (Supplementary Fig. 4g). These results indicated that HDACs, especially HDAC-1, may be involved in the process of $\beta$-catenin acetylation at Lys49 regulated by $\mathrm{BCl}-3$.

It has been reported that $\mathrm{BCl}-3$ forms a complex with $\mathrm{HDAC}-1,-3$, and -6 to control the expression of a subset of genes. ${ }^{34} \mathrm{We}$ hypothesized that Bcl-3 alters the interaction between $\beta$-catenin and HDACs. Co-IP assays showed that $\beta$-catenin bound to endogenous BCl-3, HDAC-1, HDAC-6 (Fig. 6i), and HDAC-1 but not HDAC-6, which increased in the $\beta$-catenin complex in Bcl-3-silenced cells (Fig. 6i). Our results showed that both HDAC- 1 and HDAC- 6 protein levels increased when $\mathrm{BCl}-3$ was silenced. Moreover, the interaction of HDAC- 1 and $\beta$-catenin was enhanced in $\mathrm{Bcl}-3 \mathrm{KD}$ cells, but the binding of HDAC- 6 and $\beta$-catenin did not change. These results indicated that in addition to inhibiting the expression of HDAC-1, BCl-3 could also inhibit the binding of HDAC- 1 to $\beta$-catenin, thus increasing the acetylation level of $\beta$-catenin.

Furthermore, the transcriptional activity of $\beta$-catenin was partially regulated by $\mathrm{BCl}-3$ via $\mathrm{HDAC}-1$ (Fig. 6j). These results demonstrated that $\mathrm{BCl}-3$ regulated $\mathrm{Ac}-\mathrm{K} 49$ $\beta$-catenin levels in a deacetylase-dependent manner whereby $\mathrm{Bcl}-3$ segregated HDAC1 and $\beta$-catenin to maintain a relatively high level of Ac-K49 $\beta$-catenin to promote $\mathrm{Wnt} / \beta$-catenin activity.

$\mathrm{BCl}-3$ is overexpressed in CRC tissues and correlates with CRC patient survival

We then assessed $\mathrm{BCl}-3$ mRNA expression based on the ONCOMINE Colorectal Dataset (https://www.oncomine.org/ resource/main.html) ${ }^{25}$ and found that Bcl-3 mRNA in adenocarcinoma tissues was much higher than that in normal colorectal tissues (Supplementary Fig. 5). Subsequently, both $\mathrm{BCl}-3$ and CD133 mRNA levels were found to be significantly increased in human colorectal tumors compared with their paired normal biopsies (Fig. 7a).

To further assess the clinical relevance of $\mathrm{Bcl}-3$ expression and CRC, we conducted a Kaplan-Meier survival analysis based on clinical data from GSE14333 through the bioinformatics website R2: Genomics Analysis and Visualization Platform (http://r2.amc.nl). Patients with higher levels of $\mathrm{Bcl}-3$ mRNA $(n=173)$ showed significantly lower relapse-free survival than patients whose tumors expressed lower levels of $\mathrm{Bcl}-3$ ( $n=53$; Fig. 7b). Then, 186 CRC patients (TMA-3) were categorized into positive and negative groups based on the protein expression of $\mathrm{BCl}-3$, and 
Chen et al.

a

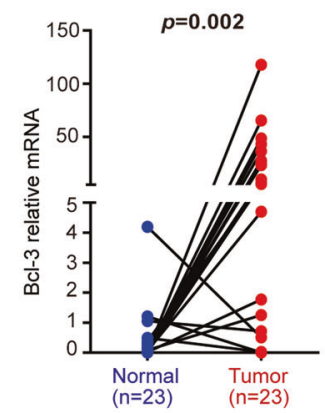

C

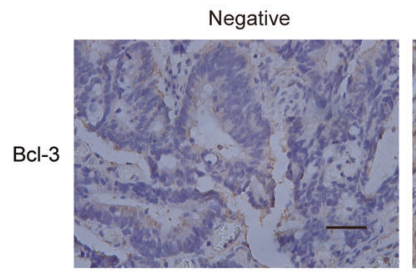

e

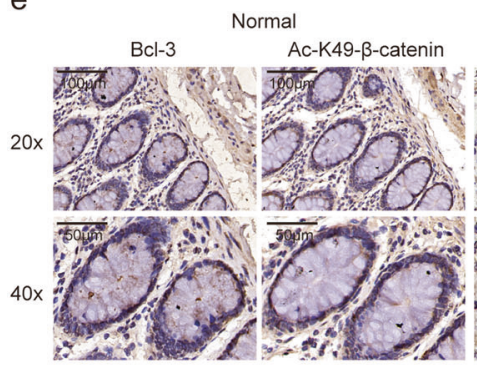

g

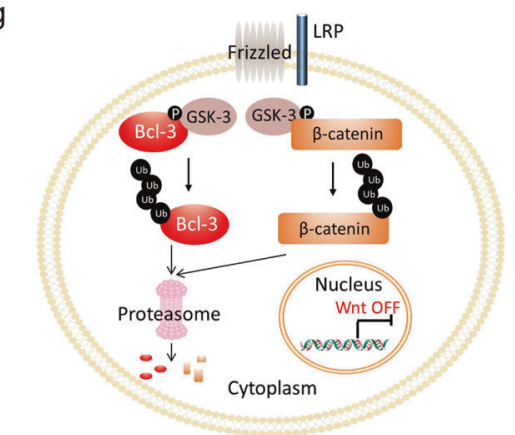

i

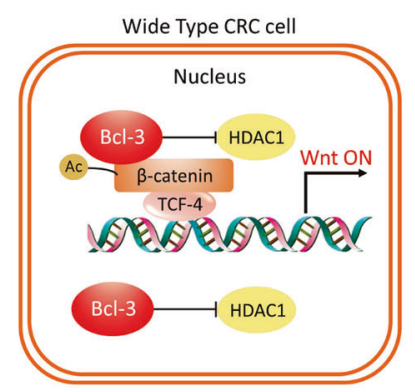

b

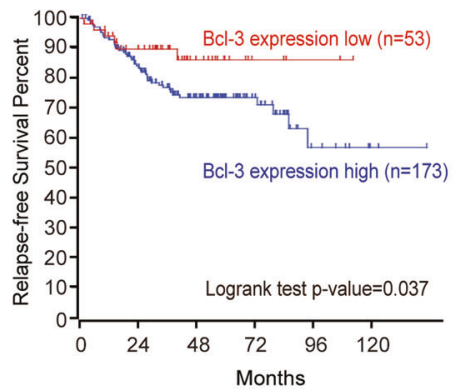

d

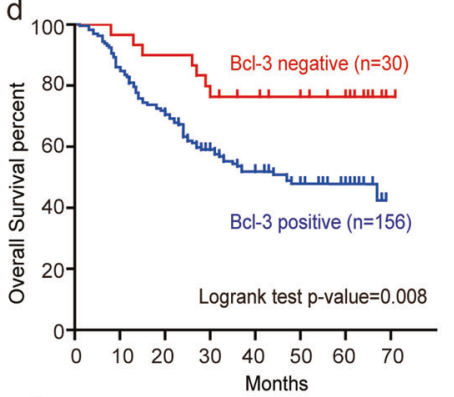

f
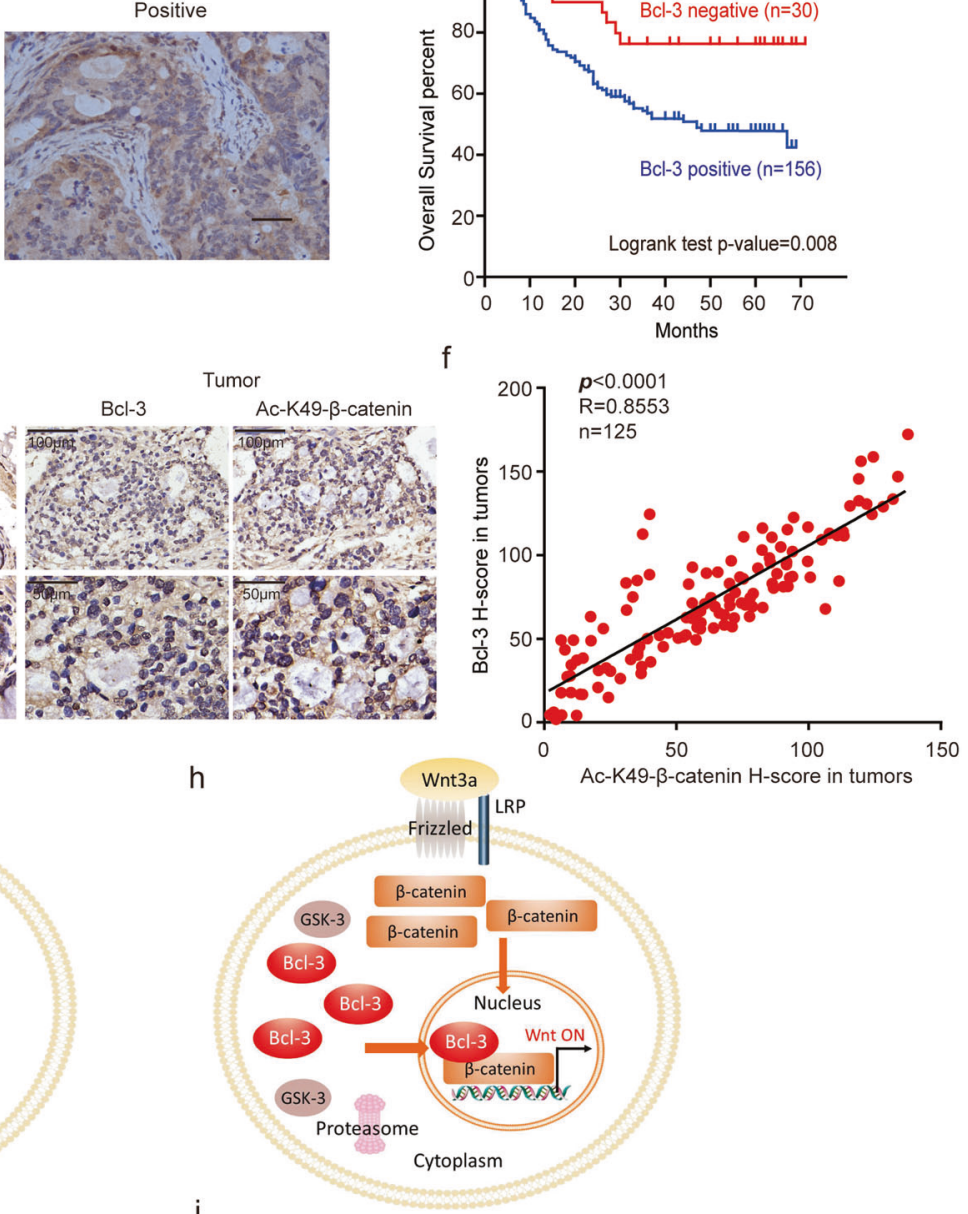

j

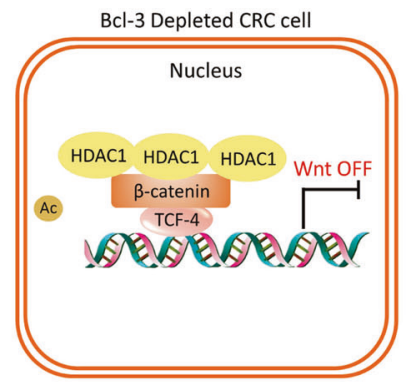

Fig. $7 \mathrm{BCl}-3$ is overexpressed in CRC tissues and correlates with CRC patient survival. a $B C l-3$ and CD133 mRNA levels in 23 matched tumors and paired normal biopsies. $p=0.0009$ for Bcl-3 and $p=0.0044$ for $C D 133$ by paired $t$-test. $\mathbf{b}$ Kaplan-Meier graph shows the survival analyses of patients with colorectal cancer based on Bcl-3 expression using R2: Genomics Analysis and Visualization Platform. c Representative images of positive and negative Bcl-3 staining in CRC patients. d Kaplan-Meier graph shows the overall survival rate in CRC patients based on Bcl-3 staining using IHC assay. e Representative images of $\mathrm{BCl}-3$ and Ac-K49- $\beta$-catenin expression based on IHC of serial sections of tissue microarrays. $\mathbf{f}$ The expression of Bcl-3 and Ac-K49- $\beta$-catenin in CRC tissue microarrays was analyzed by Spearman rank correlation coefficient analysis; $R=0.8646 ; p<0.001 ; n=125$. $\mathbf{g}$, $\mathbf{h}$ Cartoon illustration of the mechanisms by which Wnt3a increases Bcl-3 protein levels. $\mathbf{i}, \mathbf{j}$ Cartoon illustration of the mechanisms by which $\mathrm{Bcl}-3$ regulates the Wnt/ $\beta$-catenin signaling pathway 
representative images are shown in Fig. 7c. The Kaplan-Meier survival rate supported the observation that $\mathrm{Bcl}-3$ expression was significantly associated with poor survival in CRC patients (Fig. 7d).

We also examined the correlation between Bcl-3 and Ac-K49$\beta$-catenin expression in human CRC. IHC analysis was performed for $\mathrm{BCl}-3$ and $\mathrm{AC}-\mathrm{K} 49-\beta$-catenin in serial sections of colon tumor microarrays, comprising 125 tumor specimens and 14 normal biopsies (the clinical information is summarized in Supplementary Table 1). Immunochemistry analyses revealed significantly higher $\mathrm{BCl}-3$ and Ac-K49- $\beta$-catenin protein levels in colorectal tumors than in normal colons (Fig. 7e). Consistent with our previous observation, a significantly positive correlation between $\mathrm{Bcl}-3$ and Ac-K49- $\beta$-catenin was found in the tumor specimens (Fig. 7f). Taken together, these data indicate $\mathrm{Bcl}-3$ as a potential biomarker for $\mathrm{CRC}$, and the prognosis of patients with high $\mathrm{Bcl}-3$ expression was worse than that of patients with low $\mathrm{Bcl}-3$ expression.

\section{DISCUSSION}

Constitutive activation of Wnt signaling is closely associated with CRC progression and stem cell-like properties in CRC; therefore, understanding the biological basis for the observed Wnt signaling overactivation is of great value for future development of novel therapeutic strategies. Canonical Wnt/ $\beta$-catenin signaling has been implicated in the regulation of CRC proliferation, maintenance of cellular stemness and chemoresistance. As Bcl-3 is overexpressed in many human cancers and regulates stemness of colorectal CSCs, we considered a direct connection between $\mathrm{Bcl}-3$ and the $W n t / \beta$-catenin signaling pathways. In this study, we demonstrated that $\mathrm{BCl}-3$ is required for $W n t / \beta$-catenin transcriptional activity in CRC cells, which is achieved by maintaining the level of Ac-K49 $\beta$-catenin. In summary, without Wnt3a stimulation, both $\mathrm{BCl}-3$ and $\beta$-catenin were maintained at relatively low levels due to the phosphorylation of GSK-3 and degradation of the ubiquitin-proteasome pathway (Fig. 7g). Under Wnt3a treatment, both proteins were released from GSK-3 and the degradation complex. Next, accumulated $\mathrm{BCl}-3$ and $\beta$-catenin translocated into the nucleus to form the $\mathrm{BCl}-3-\beta$-catenin complex on the promoter of Wnt target genes (Fig. 7h). In wild-type CRC cell nuclei, Bcl-3 and $\beta$-catenin formed a transcriptional complex with TCF-4 on Wnt target gene promoters, and $\beta$-catenin was acetylated by CBP and p300 (Fig. 7i). When $\mathrm{Bcl}-3$ was silenced, $\mathrm{HDAC}-1$ was overexpressed, and more HDAC-1 bound with $\beta$-catenin to significantly decrease $\beta$-catenin acetylation levels, which resulted in suppressed gene expression (Fig. 7j).

Recently, another study addressed some of the same issues as those presented here. ${ }^{42}$ These two independent pieces of work arrived at essentially the same conclusions, further validating the results of both studies. However, our work demonstrated in detail that $\mathrm{BCl}-3$ promotes the colorectal CSC phenotype and chemoresistance by enhancing $W n t / \beta$-catenin signaling. We further revealed the critical role of the acetylation of $\beta$-catenin at lysine 49 in Wnt/ $\beta$-catenin signaling, which was modulated by Bcl-3.

Aside from the phosphorylation of GSK-3 at S394/398, other kinases, including Akt, Erk2, and IKK, participate in $\mathrm{BCl}-3$ phosphorylation and regulate its transcriptional activity. ${ }^{43}$ The phosphorylation of $\mathrm{BCl}-3$ at Ser33 through Akt could promote $\mathrm{BCl}-$ 3 stabilization and nuclear localization. ${ }^{43}$ Moreover, the deubiquitinase enzyme CYLD removes the K63-linked ubiquitin chain on $\mathrm{Bcl}-3$ to prevent $\mathrm{BCl}-3$ nuclear accumulation. ${ }^{43}$ These results indicate areas for further exploration of the mechanism by which Wnt induces $\mathrm{Bcl}-3$ nuclear translocation, and whether these kinases and phosphorylation sites on $\mathrm{Bcl}-3$ are required for Wnt3ainduced $\mathrm{BCl}-3$ nuclear translocation also need further verification.

In the process of oligodendrocyte differentiation, HDAC-1 competes with $\beta$-catenin for TCF7L2 interaction to negatively regulate Wnt target gene expression. ${ }^{44}$ However, in breast and ovarian cancer, HDAC- 1 and HDAC-7 are overexpressed in CSCs and are necessary to maintain CSCs. In our work, HDAC-1 increased in Bcl-3-silenced cells, and increased levels of HDAC-1 bound to $\beta$-catenin were found in $\mathrm{Bcl}-3$-depleted cells. In mESCs, $\mathrm{BCl}-3$ depletion decreased the binding of acetylated histone 3 on the Oct4 promoter. $^{20}$ Unfortunately, we found that the level of acetylated $\mathrm{H} 3$ did not change in $\mathrm{BCl}-3 \mathrm{KD}$ cells (data not shown). Whether Bcl-3 influences the binding of acetylated $\mathrm{H} 3$ to the Wnt target gene promoter remains to be determined.

Because of the crucial role of Wnt signaling in CRC progression and colorectal CSC maintenance, inhibition of Wnt/ $\beta$-catenin signaling by targeting $\mathrm{BCl}-3$ may offer a therapeutic approach in CRC treatment.

\section{DATA AVAILABILITY}

All data and materials are available to the researchers once published.

\section{ACKNOWLEDGEMENTS}

We thank all Zhang laboratory members for comments and the staff of the core facility of the Institute of Nutrition and Health, Shanghai Institutes for Biological Sciences, Chinese Academy of Sciences for assistance. This study was funded by the National Program on Key Research (2018YFA0107500 and 2016YFC1302400), National Basic Research Program (2014CB541904 and 2014CB943600), National Natural Science Foundation of China $(91742113,31570902,81702950,81772798$, 91949102 and 81771752), Natural Science Foundation of Shanghai (14ZR1426300, 18ZR1424400, 18ZR1446400 and 18431902700), China Postdoctoral Science Foundation (2017M611633), and Guangzhou Key Medical Discipline Construction Project Fund.

\section{AUTHOR CONTRIBUTIONS}

X.C., S.L., and X.Z. conceptualization; X.C., S.L., and C.W. data curation; X.C., S.L., C.W., Y.J., Q.W., Y.T., H.Z., Y.Z., Y.H., C.L., D.Y., D.L., and W.J. data collection and analysis; X.C., S.L., E. C., Y.L., M.W., and X.Z. methodology; X.C., S.L., C.W., and X.Z. writing; M.W., S.C., and X.Z. funding acquisition; and S.L. and X.Z. project administration.

\section{ADDITIONAL INFORMATION}

The online version of this article (https://doi.org/10.1038/s41392-020-0138-6) contains supplementary material, which is available to authorized users.

Competing interests: The authors declare no competing interests.

Consent for publication: All authors agree to publish this manuscript.

Ethics approval: This project was approved by the ethics committee of Zhongshan Hospital, Shanghai, China. Clinical samples were collected from 2008-2010. All patients enrolled signed informed consent forms. CRC was confirmed after surgery by pathologists. Tumors and adjacent tissues were collected during surgeries and were directly dissected and frozen in liquid nitrogen.

\section{REFERENCES}

1. Siegel, R. L., Miller, K. D. \& Jemal, A. Cancer statistics, 2018. CA Cancer J. Clin. 68, 7-30 (2018).

2. Visvader, J. E. \& Lindeman, G. J. Cancer stem cells: current status and evolving complexities. Cell Stem Cell 10, 717-728 (2012).

3. Moore, N. \& Lyle, S. Quiescent, slow-cycling stem cell populations in cancer: a review of the evidence and discussion of significance. J. Oncol. 2011, https://doi. org/10.1155/2011/396076 (2011).

4. O'Brien, C. A., Pollett, A., Gallinger, S. \& Dick, J. E. A human colon cancer cell capable of initiating tumour growth in immunodeficient mice. Nature 445, 106-110 (2007)

5. Ricci-Vitiani, L. et al. Identification and expansion of human colon-cancerinitiating cells. Nature 445, 111-115 (2007).

6. Clevers, H. \& Nusse, R. Wnt/beta-catenin signaling and disease. Cell 149, 1192-1205 (2012).

7. Myant, K. B. et al. ROS production and NF-kappaB activation triggered by RAC1 facilitate WNT-driven intestinal stem cell proliferation and colorectal cancer initiation. Cell Stem Cell 12, 761-773 (2013). 
8. Zeilstra, J. et al. Deletion of the WNT target and cancer stem cell marker CD44 in $\mathrm{Apc}(\mathrm{Min} /+)$ mice attenuates intestinal tumorigenesis. Cancer Res. 68, 3655-3661 (2008).

9. Ordonez-Moran, P., Dafflon, C., Imajo, M., Nishida, E. \& Huelsken, J. HOXA5 counteracts stem cell traits by inhibiting wnt signaling in colorectal cancer. Cancer Cell 28, 815-829 (2015).

10. Liu, C. et al. Control of beta-catenin phosphorylation/degradation by a dualkinase mechanism. Cell 108, 837-847 (2002).

11. Aberle, H., Bauer, A., Stappert, J., Kispert, A. \& Kemler, R. Beta-catenin is a target for the ubiquitin-proteasome pathway. EMBO J. 16, 3797-3804 (1997).

12. Franzoso, G. et al. The oncoprotein Bcl-3 can facilitate NF-kappa B-mediated transactivation by removing inhibiting p50 homodimers from select kappa $B$ sites. EMBO J. 12, 3893-3901 (1993).

13. Fujita, T., Nolan, G. P., Liou, H. C., Scott, M. L. \& Baltimore, D. The candidate protooncogene bcl-3 encodes a transcriptional coactivator that activates through NFkappa B p50 homodimers. Genes Dev. 7, 1354-1363 (1993).

14. Wakefield, A. et al. Bcl3 selectively promotes metastasis of ERBB2-driven mammary tumors. Cancer Res. 73, 745-755 (2013).

15. Chen, $\mathrm{X}$. et al. BCl-3 regulates TGFbeta signaling by stabilizing Smad3 during breast cancer pulmonary metastasis. Cell Death Dis. 7, e2508 (2016).

16. Wu, J., Li, L., Jiang, G., Zhan, H. \& Wang, N. B-cell CLL/lymphoma 3 promotes glioma cell proliferation and inhibits apoptosis through the oncogenic STAT3 pathway. Int. J. Oncol. 49, 2471-2479 (2016).

17. Liu, Z. et al. The IkappaB family member Bcl-3 stabilizes c-Myc in colorectal cancer. J. Mol. Cell Biol. 5, 280-282 (2013).

18. Urban, B. C. et al. BCL-3 expression promotes colorectal tumorigenesis through activation of AKT signalling. Gut 65, 1151-1164 (2016).

19. Tang, W. et al. The B-cell tumor promoter BCl-3 suppresses inflammationassociated colon tumorigenesis in epithelial cells. Oncogene 35, 6203-6211 (2016).

20. Chen, C. Y. et al. Bcl3 bridges LIF-STAT3 to Oct4 signaling in the maintenance of naive pluripotency. Stem Cells 33, 3468-3480 (2015).

21. Kang, S. et al. Adequate concentration of $B$ cell leukemia/lymphoma $3(\mathrm{BCl} 3)$ is required for pluripotency and self-renewal of mouse embryonic stem cells via downregulation of Nanog transcription. BMB Rep. 51, 92-97 (2018).

22. Yeung, T. M., Gandhi, S. C., Wilding, J. L., Muschel, R. \& Bodmer, W. F. Cancer stem cells from colorectal cancer-derived cell lines. Proc. Natl Acad. Sci. USA 107, 3722-3727 (2010).

23. Chen, K. L. et al. Highly enriched CD133(+)CD44(+) stem-like cells with CD133(+) CD44(high) metastatic subset in HCT116 colon cancer cells. Clin. Exp. Metastasis 28, 751-763 (2011).

24. Kang, D. W. et al. Targeting phospholipase D1 attenuates intestinal tumorigenesis by controlling beta-catenin signaling in cancer-initiating cells. J. Exp. Med. 212, 1219-1237 (2015).

25. Skrzypczak, M. et al. Modeling oncogenic signaling in colon tumors by multidirectional analyses of microarray data directed for maximization of analytical reliability. PLOS ONE 5, https://doi.org/10.1371/journal.pone.0013091 (2010).

26. Heissmeyer, V., Krappmann, D., Wulczyn, F. G. \& Scheidereit, C. NF-kappaB p105 is a target of IkappaB kinases and controls signal induction of Bcl-3-p50 complexes. EMBO J. 18, 4766-4778 (1999).

27. Brenne, A. T. et al. High expression of BCL3 in human myeloma cells is associated with increased proliferation and inferior prognosis. Eur. J. Haematol. 82, 354-363 (2009).

28. Rebollo, A. et al. Bcl-3 expression promotes cell survival following interleukin-4 deprivation and is controlled by AP1 and AP1-like transcription factors. Mol. Cell. Biol. 20, 3407-3416 (2000).

29. Elliott, S. F., Coon, C. I., Hays, E., Stadheim, T. A. \& Vincenti, M. P. Bcl-3 is an interleukin-1-responsive gene in chondrocytes and synovial fibroblasts that activates transcription of the matrix metalloproteinase 1 gene. Arthritis Rheum. 46, 3230-3239 (2002).

30. Hu, X. et al. Activation of nuclear factor-kappaB signaling pathway by interleukin1 after hypoxia/ischemia in neonatal rat hippocampus and cortex. J. Neurochem. 93, 26-37 (2005).

31. Brocke-Heidrich, K. et al. BCL3 is induced by IL- 6 via Stat3 binding to intronic enhancer HS4 and represses its own transcription. Oncogene 25, 7297-7304 (2006).

32. Kuwata, H. et al. IL-10-inducible Bcl-3 negatively regulates LPS-induced TNF-alpha production in macrophages. Blood 102, 4123-4129 (2003).

33. Folco, E. J., Rocha, V. Z., Lopez-llasaca, M. \& Libby, P. Adiponectin inhibits proinflammatory signaling in human macrophages independent of interleukin-10. J. Biol. Chem. 284, 25569-25575 (2009).

34. Viatour, P. et al. GSK3-mediated BCL-3 phosphorylation modulates its degradation and its oncogenicity. Mol. Cell 16, 35-45 (2004).

35. Clevers, H. Wnt/beta-catenin signaling in development and disease. Cell 127, 469-480 (2006).

36. Moon, R. T., Kohn, A. D., De Ferrari, G. V. \& Kaykas, A. WNT and beta-catenin signalling: diseases and therapies. Nat. Rev. Genet. 5, 691-701 (2004).

37. Imbert, A., Eelkema, R., Jordan, S., Feiner, H. \& Cowin, P. Delta N89 beta-catenin induces precocious development, differentiation, and neoplasia in mammary gland. J. Cell Biol. 153, 555-568 (2001).

38. Wolf, D., Rodova, M., Miska, E. A., Calvet, J. P. \& Kouzarides, T. Acetylation of beta-catenin by CREB-binding protein (CBP). J. Biol. Chem. 277, 25562-25567 (2002).

39. Levy, L. et al. Acetylation of beta-catenin by p300 regulates beta-catenin-Tcf4 interaction. Mol. Cell. Biol. 24, 3404-3414 (2004).

40. Ge, X., Jin, Q., Zhang, F., Yan, T. \& Zhai, Q. PCAF acetylates \{beta\}-catenin and improves its stability. Mol. Biol. Cell 20, 419-427 (2009).

41. Emami, K. H. et al. A small molecule inhibitor of beta-catenin/CREB-binding protein transcription [corrected]. Proc. Natl Acad. Sci. USA 101, 12682-12687 (2004).

42. Legge, D. N. et al. BCL-3 promotes a cancer stem cell phenotype by enhancing beta-catenin signalling in colorectal tumour cells. Dis. Model. Mech. 12, https:// doi.org/10.1242/dmm.037697 (2019).

43. Wang, V. Y. et al. Bcl3 phosphorylation by Akt, Erk2, and IKK is required for its transcriptional activity. Mol. Cell 67, 484-497 e485 (2017).

44. Ye, F. et al. HDAC1 and HDAC2 regulate oligodendrocyte differentiation by disrupting the beta-catenin-TCF interaction. Nat. Neurosci. 12, 829-838 (2009).

(c) (i) Open Access This article is licensed under a Creative Commons Attribution 4.0 International License, which permits use, sharing, adaptation, distribution and reproduction in any medium or format, as long as you give appropriate credit to the original author(s) and the source, provide a link to the Creative Commons license, and indicate if changes were made. The images or other third party material in this article are included in the article's Creative Commons license, unless indicated otherwise in a credit line to the material. If material is not included in the article's Creative Commons license and your intended use is not permitted by statutory regulation or exceeds the permitted use, you will need to obtain permission directly from the copyright holder. To view a copy of this license, visit http://creativecommons. org/licenses/by/4.0/.

() The Author(s) 2020 